\title{
Could virtual reality applications pose real risks to children and adolescents? A systematic review of ethical issues and concerns
}

\author{
Polyxeni Kaimara $^{1} \cdot$ Andreas Oikonomou $^{2} \cdot$ Ioannis Deliyannis ${ }^{1}$
}

Received: 12 November 2020 / Accepted: 20 July 2021 / Published online: 3 August 2021

(c) The Author(s), under exclusive licence to Springer-Verlag London Ltd., part of Springer Nature 2021

\begin{abstract}
Virtual reality technologies (VRTs) are high-tech human-computer interfaces used to develop digital content and can be applied to multiple different areas, often offering innovative solutions to existing problems. A wide range of digital games is being also developed with VRTs and together with their components, the games' structural elements are appealing to children and engaging them more in virtual worlds. Our research interest is directed towards children's development and the effects of VRTs within gaming environments. Contemporary psychology studies perceive human development as a holistic and lifelong process with important interrelationships between physical, mental, social and emotional aspects. For the objectives and scope of this work, we examine children development across three domains: physical, cognitive and psychosocial. In this context, the authors review the literature on the impact of VRTs on children, in terms of software and hardware. Since research requires an wide-ranging approach, we study the evidence reported on the brain and neural structure, knowledge, behaviour, pedagogy, academic performance, and wellness. Our main concern is to outline the emerging ethical issues and worries of parents, educators, ophthalmologists, neurologists, psychologists, paediatricians and all relevant scientists, as well as the industry's views and actions. The systematic review was performed on the databases Scopus, IEEE Xplore, PubMed, and Google Scholar from 2010 to 2020 and 85 studies were selected. The review concluded that findings remain contradictory especially for the psychosocial domain. Official recommendations from organizations and well-documented researches by academics on child well-being are reassuring if health and safety specifications and particularly the time limit are met. Research is still ongoing, constantly updated and consist of a priority for the scientific community given that technology evolves.
\end{abstract}

Keywords Child development $\cdot$ Ethical issues $\cdot$ Games $\cdot$ Impact of technology $\cdot$ Safety $\cdot$ Virtual reality technologies

\section{Introduction}

Virtual reality (VR) is an immersive technology whose roots date back to the nineteenth century when the first 360-degree art through panoramic murals began to appear, though the

Polyxeni Kaimara

a16kaim@ionio.gr

Andreas Oikonomou

aoikonomou@aspete.gr

Ioannis Deliyannis

yiannis@ionio.gr

1 Department of Audio and Visual Arts, Ionian University, Tsirigoti Sq. 7, 49100 Corfu, Greece

2 School of Pedagogical and Technological Education (ASPETE), Alexandrou Papanastasiou 13, Thessaloniki, Greece term was first used in the $60 \mathrm{~s}$ by Heilig (Freina and Ott 2015). Sensorama Simulator System and Telesphere Mask, possibly the first head-mounted display, were designed by Heilig $(1960,1962)$, which involved multiple senses to create an immersive VR space while providing a pedagogical dimension. Sensorama Simulator System produced a complete illusion through the multisensory experience. One of the applications made especially for Sensorama, involved the experience of riding a motorcycle through 3D, colour film, combined with directional sound, aromas, wind and vibrations (Ijsselsteijn 2005; Freina and Ott 2015). However, the term VR was coined by Jaron Lanier in 1986 (Lanier and Biocca 1992; Heim 1998). In short, virtual reality technologies (VRTs) can be defined as high-tech human-computer interfaces which include real-world simulation and interactions through multiple sensory channels, prompting users to interact with virtual objects in a way that resembles the 
way they would interact in real life (Freina and Ott 2015). Along with VR, literature also includes the term "virtual environments" (VEs). The unique features of VEs that raise academic debates about VR impact on humans are usually referred to as the "three I's": (1) immersion, (2) interactivity, and (3) information intensity (Heim 1998). Burdea and Coiffet (2003) suggested another dimension of "I", the imagination, which relates to the users' aptitude to perceive non-existent things and their willingness to believe that they find themselves in a VE, even when they know that are in a different natural environment. Freina and Ott (2015) also indicated the user involvement with the environment and narrative, as one of the key principles of VEs. Two types of VEs are indicated, the non-immersive and the immersive (Freina and Ott 2015). The first type describes the simulation environment, employing a desktop computer. Though desktop computer-based VEs are considered to be nonimmersive, in fact, are defined as desktop semi-immersive VEs (Fowler 2015). The second type of immersion related to the feeling and perception of being physically present in the non-physical world, using special equipment and portable smart devices (PSDs), (e.g. smartphones and tablets, Google Lens, leap motion, and wearables such as head-mounted displays (HMDs), gloves, smartwatches, glasses, clothes, and fabrics). Specially designed HMDs include Facebook's Oculus Rift, Google Cardboard, Nintendo Labo VR Kit, Sony Playstation VR, HTC Vive and Samsung Gear VR (Sobel 2019).

As the goal of VE is to place users in a 3D environment and give them the feeling of belonging to a space that looks authentic, the most important features of such artificial environments are the sense of presence and immersion. Although initially there was a tendency to use these terms interchangeably, presence is a state of consciousness, that is the psychological sense of being in a virtual environment while immersion is an objective description of what a particular system provides (Slater et al. 1995). According to Lee (2004, p. 27) presence is defined as "a psychological state in which virtual objects are experienced as actual objects in either sensory or nonsensory ways". On the other hand, immersion is an objective characteristic of the technology which relies on the technical capabilities of a VR system to produce sensory fidelity that leads to a sense of presence (Dalgarno and Lee 2010). In other words, in a VRE presence and immersion are interrelated as they both involve a psychological component, i.e. presence is the subjective response to an objective immersion level (Lombard and Ditton 1997; Slater 2003).

In terms of pedagogy, three features underpin the quality of a VE: (1) representational fidelity, (2) learner interaction and (3) avatar that constitutes the identity construction. Representational fidelity refers to the quality of the display to provide high realism, the smooth display of view changes and object motion, the consistency of object behaviour, the quality of the user representation within the 3D virtual learning environments (VLEs), the spatial audio, the kinaesthetic, and the tactile force feedback (Dalgarno and Lee 2010; Fowler 2015). Interaction is the dynamic concept resulting from the embodiment experience (actions, verbal and non-verbal communication, control of environment attributes, construction of objects, and behaviours) by the user. The third feature that is usually embedded into the VE, but not necessarily in all VEs, is the avatar, which is the user's representation. The avatar can communicate, express emotions, create objects, and generally act following the user's instructions.

VRTs cover a wide range of interventions such as military, healthcare, marketing, entertainment, gaming, business, and education with highly promising learning outcomes. Numerous digital games are developed with VRTs. Along with VRTs components (i.e. immersion, intensity, presence, involvement, imagination, interactivity), games draw together powerful structural elements, (i.e. rules, goals and objectives, feedback, challenges, interaction and story) providing fun, enjoyment, pleasure, intense and passionate involvement, and finally engagement (Prensky 2007). VRTs components and games' structural elements engage children and involve them even more in the virtual worlds.

Children's engagement with immersive technologies is constantly increasing in all parts of the world. Day by day it turns out that innovative applications are effective in treating and improving children daily living skills with or without disabilities. Given that nowadays PSDs are affordable and accessible to a large part of the population, technology could facilitate equitable access, participation and inclusion for children. Currently, due to the COVID19 pandemic and consequently social distancing, thanks to networking, children can engage in activities that they could not otherwise do, and communicate, collaborate and co-create with their classmates. Through immersive learning environments, children have access to the outside world and interact with people and objects, even if they remain in the classroom or at home.

Health, safety and ethical concerns arising from VR use by children reveal an interdisciplinary research field, that examines issues from many different perspectives as VRTs extend to game production usually employing specialized hardware, e.g. HMDs, gloves and/or small screens, e.g. smartphones and tablets and often demand internet connectivity. Indicatively, Behr et al. (2005), Young (2009), Kade (2015), Madary and Metzinger (2016), Bailey and Bailenson (2017), Kenwright (2018), and Parsons (2019) explored the effect of VRTs and provided evidence of their impact, such as cybersickness, cognition, confusion between real and virtual worlds, addiction, etc. 
Our research interest is directed towards children's development and the effects of VRTs within gaming environments. Contemporary psychology studies perceive human development as a holistic and lifelong process with important interrelationships between physical, mental, social, and emotional aspects (Shaffer and Kipp 2014; Spielman et al. 2020) (Fig. 1).

Studying the impact of VRTs especially on children, both those with special educational needs and their typically developing peers, demands a wide-ranging approach, considering the evidence on the brain and neural structure, knowledge, behaviour, pedagogy, academic performance, and wellness.

The purpose of this systematic review is to mapping the field of the emerging ethical issues and worries of parents, educators, ophthalmologists, neurologists, psychologists, paediatricians and all relevant scientists, as well as the industry's views and actions. The literature review process involved the examination of longitudinal and experimental studies related to VRTs and games, including search terms and keywords, databases, and explicit inclusion criteria. Therefore, our search strategy was realized with a combination of terms and keywords for VRTs and games, children, and developmental domains. Research findings on the effects of VRTs and gaming remain contradictory. On the one hand, studies are proving the positive impact on cognitive, motivational, emotional, social development, and enhancement of both learning and training tasks (Shaffer et al. 2005; Van Eck 2006; Gee 2008; Dalgarno and Lee 2010; Granic et al. 2014; Fowler 2015; Passig et al. 2016; Palaus et al. 2017; Molina-Carmona et al. 2018; Kaimara and Deliyannis 2019;

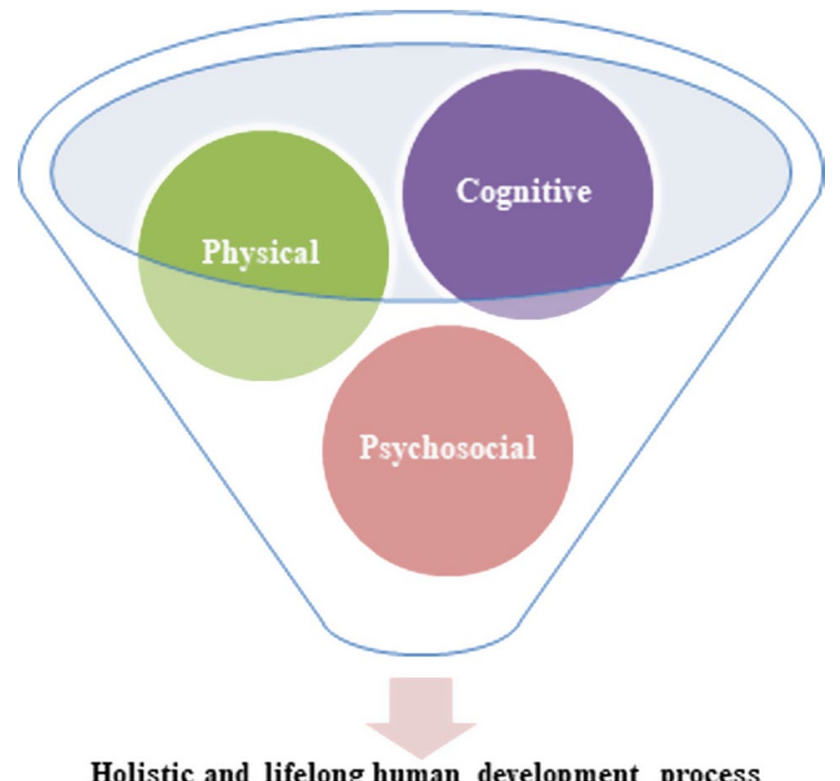

Holistic and lifelong human development process
Mayer 2019; Makransky et al. 2019; Checa and Bustillo 2020; Kaimara et al. 2020b; Chang et al. 2020; Pallavicini and Pepe 2020) while other researchers argued that VR and games have the potential to elicit strong negative emotional consequences (Lavoie et al. 2020), could lead to distraction or even addiction, sleep patterns disruption, cardio-metabolic deficiencies, obesity, etc. (Calvert et al. 2013; Tate et al. 2013; Turel et al. 2016; Thierer and Camp 2017; Fuller et al. 2017; Kenney and Gortmaker 2017; Turel et al. 2017). Therefore, beyond the potential positive impact of VLEs and games, the study is directed to the claims about their possible negative effects on children's overall development due to software and specialized devices and screens (Madary and Metzinger 2016; Boyle et al. 2016; National Academies of Sciences Engineering and Medicine 2018; UK Department for Business Energy \& Industrial Strategy 2020).

Given the following considerations: (1) VR is a cuttingedge technology that has been evolving rapidly in recent years and is often combined with other emerging technologies applied in many areas of daily life, (2) a wide range of longitudinal impact studies is not yet matured enough to afford data for any secure conclusions, and (3) contemporary psychology perceives child development, not as a fragmentary but as a holistic process, it is essential to provide an overview of the concerns regarding the effect of VR use on overall children's development. For the scope and objectives of the current systematic review, it was decided to identify relevant studies to this particular subject across three developmental domains (i.e. physical, cognitive, and psychosocial), underlining that one domain has significant interconnections with others (Shaffer and Kipp 2014; Sobel 2019; Spielman et al. 2020). Within this context, the systematic review seeks to increase the literature on concerns regarding the impact of VRTs on children development by answering a primary research question followed by three sub-questions.

\subsection{Overarching question}

RQ1 In which domains of child development are the potential risks of virtual reality (software and hardware) identified?

\subsection{Sub-questions}

RQ1a Which are the most frequently identified concerns when children use virtual reality for their physical development?

Fig. 1 Holistic and lifelong human development process 
RQ1b Which are the most frequently identified concerns when children use virtual reality for their cognitive development?

RQ1C Which are the most frequently identified concerns when children use virtual reality for their psychosocial development?

\section{Methodology}

\subsection{Study design}

The authors decided to explore the ethical issues that may arise in connection with VR effects on children, driven by (1) their personal ethics as they design and develop educational applications with virtual and augmented reality addressed to special educational needs students and their typically developing peers in inclusive settings and (2) the pervasive negative reactions to educational technology innovations, which are flooding the Internet and being promoted by a portion of media and social networking, influencing public opinion. We first looked for official reports from medical and psychological associations and universal organizations to determine the extent of the issue and scientific research directions. We then recorded the most frequently reported concerns and found that they extend to all three aspects of child development. Thus, both the primary research question and its analysis into the three sub-questions emerged. It was decided that only with a systematic literature review we could map the field, identify research trends and reach safe conclusions. We estimated that we should include research articles and other systematic reviews, as the aim of this review was not to repeat the searches, assessment of study eligibility, and assessment of the risk of bias or meta-analyses from the included reviews, but rather to provide an overall picture of findings for our particular questions (Aromataris et al. 2015). Although the organizations' reports and working papers are considered grey literature and can make important contributions to a systematic review (Charrois 2015; Paez 2017), we excluded them from the review studies and we utilised them only as a starting point for the research, i.e. by evaluating keywords, metadata, and recommendations sourced by the above dataset. Extending the steps provided by the widely accepted PRISMA statement (Moher et al. 2010), we followed the research methodology proposed by Koutsos et al. (2019) which consists of six stages: (1) Scoping: a comprehensive protocol was developed starting with the research questions and the steps to be followed, which was approved by all the authors, (2) Planning: a search strategy upon search terms and keywords, database sources, and inclusion/exclusion criteria, was developed, (3) Identification-Search process: search and check of publications by each author independently were performed, (4) Screening articles: citation management, removal of duplicates via Mendeley Reference Manager, and exclusion of the studies emerged based on title and abstract, (5) Eligibility-Assessment: use of inclusion and exclusion criteria, critical reading of full-text articles for assessment and creation of a publication list using excel sheets, and (6) Presentation: presentation of the results, synopsis of findings and recommendations, limitations and further research, and conclusions. A PRISMA flowchart is used to present the different phases of the systematic and map out the number of articles identified, included or excluded, and the reasons for these exclusions. A table was also drawn up listing the specific concerns identified by developmental domain (see Fig. 2 and Table 1 in the Results section).

The search was conducted from May to October 2020. Next, the strategy of the literature review process is presented in detail, including search terms and keywords, database search, eligibility criteria, and data collection.

\subsection{Search terms and keywords-strategy}

The process used to determine the search terms and keywords was based on the Boolean search strategy (Brereton et al. 2007; Bello Aliyu 2017). A Boolean search strategy was formed by combining terms and keywords derived from three groups: "virtual reality", "childhood", and "the potential risks of developmental domains". This search strategy allows us to identify all combinations of terms that appear in the literature. The terms within each group were combined with "OR", and three groups were linked with "AND":

1. Terms and alternatives keywords used for virtual reality were ("virtual reality" OR "VR" OR "virtual environments" OR "head-mounted display" OR "HMD*" OR "screens" OR "devices")

2. Terms used for the childhood were ("child*" OR "adolescents")

3. Terms used for the potential risks of developmental domains were ("cybersickness" OR "obesity" OR "visual*" OR "eyestrain" OR "sleep disorders" OR "cognition" OR "learning" OR "confusion" OR "anxiety" OR "addiction" OR "personality problems" OR "social*" OR "isolation" OR "social gap" OR "psychological disorders" OR "psychiatric disorders")

\subsection{Database search}

An initial search was performed through online digital scientific databases, major journal databases aiming at documenting journal papers, articles in conference proceedings, international and national organizations sites of similar reflection to map the topic and to identify the 
Fig. 2 Systematic review flowchart based on PRISMA. Adapted by Moher et al. (2010)

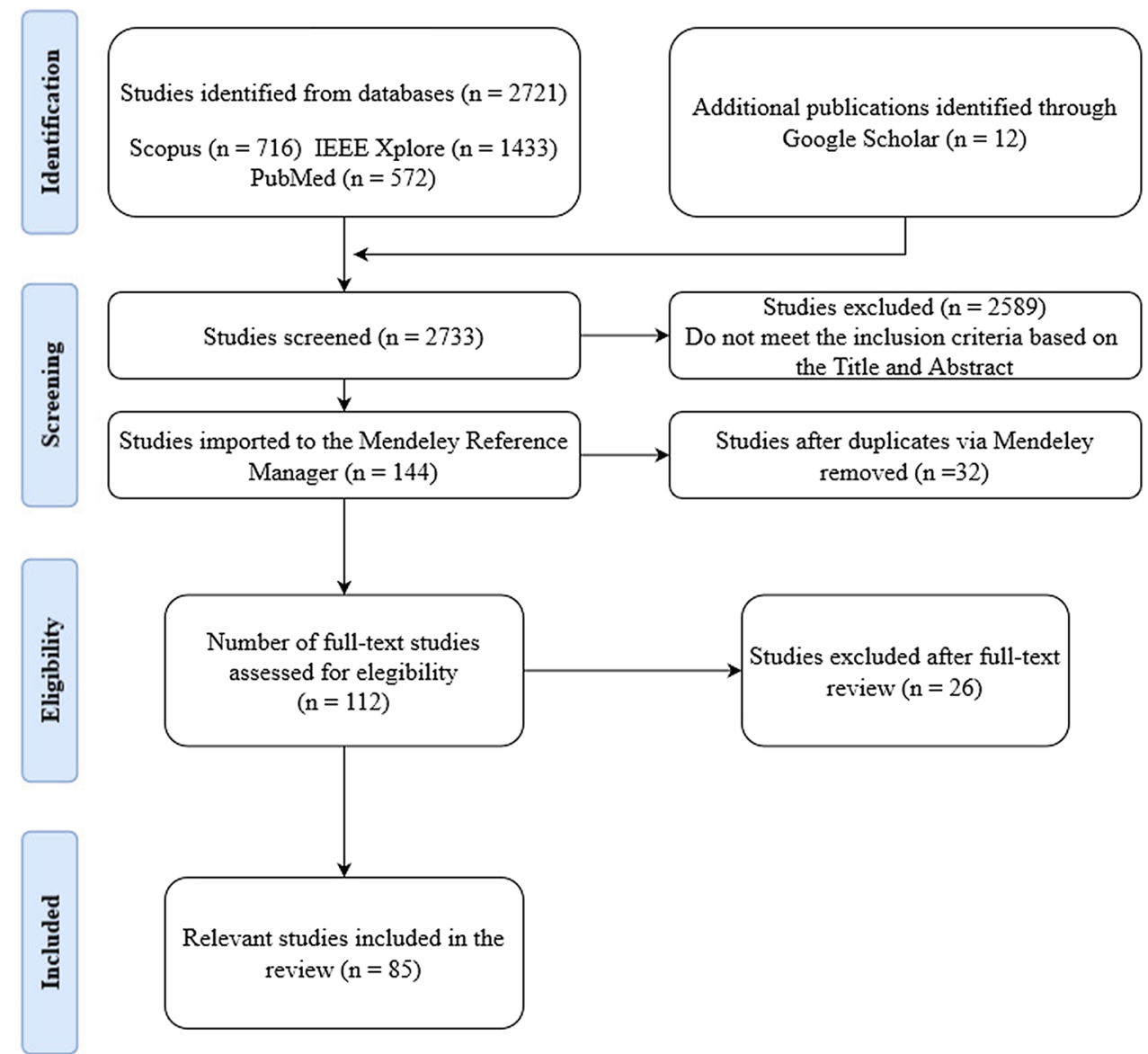

keywords. A snowballing technique was utilized too, in which citation tracking was implemented to detect relevant studies. Finally, two interdisciplinary research databases were used to provide a thorough search, SCOPUS and ScienceDirect and two specific databases, IEEE Xplore and PubMed. We extended our search based on the eligibility criteria using Google Scholar to identify other relevant studies. We also used the professional network for scientists and researchers "Researchgate" to request a full-text whether full-text articles were not available.

\subsection{Eligibility criteria}

The studies along with the search terms and keywords had to meet five criteria to be included in the review:

1. studies published between 2010 and 2020 .

2. studies published in English.

3. studies published in peer-reviewed journals.
4. studies focused, in particular, on childhood and adolescence. In the areas we did not have enough data due to the bioethics of research with children, we included studies with younger university students.

5. studies with human subjects.

\section{Results}

As mentioned, the literature review was guided by the overarching question and three sub-questions. A twophase procedure was followed to collect the studies for review. In the first phase, the studies were identified when searching for terms and keywords in databases. Next, the studies were screened for their relevance based on their titles and abstracts. It was then ascertained whether the studies met the inclusion criteria. When a study was eligible for inclusion, it was stored in the Mendeley Reference Manager Library and duplicates removed. In the second phase, a more in-depth study of the identified documents by reading the full text to be decided whether they would 
Table 1 Total number of articles per developmental domain categorized by a particular area

\begin{tabular}{|c|c|c|}
\hline 1 & Physical developmental $\left(n^{*}=28\right)$ & $\begin{array}{l}\text { Identified } \\
\text { articles }\end{array}$ \\
\hline & Cybersickness & 6 \\
\hline & Obesity & 14 \\
\hline & Radiation & 2 \\
\hline & Sleep disorders & 7 \\
\hline & Visual symptoms & 8 \\
\hline \multirow[t]{5}{*}{2} & Cognitive development $\left(n^{*}=38\right)$ & $\begin{array}{l}\text { Identified } \\
\text { articles }\end{array}$ \\
\hline & Attention & 10 \\
\hline & Learning & 26 \\
\hline & No specific area (general cognition) & 6 \\
\hline & Spatial cognition & \\
\hline \multirow[t]{7}{*}{3} & Psychological developmental $\left(n^{*}=29\right)$ & $\begin{array}{l}\text { Identified } \\
\text { articles }\end{array}$ \\
\hline & Addiction & 16 \\
\hline & Anxiety & 5 \\
\hline & Emotional effects & 8 \\
\hline & Internet Gaming Disorder & 9 \\
\hline & Prosocial behaviour & 6 \\
\hline & Social behaviour & 11 \\
\hline
\end{tabular}

$* n$, number of articles

be included in the review. A reference list and a table were then created, where identified documents were classified to the search terms. Publication information created a table containing the Author(s), Date of publication, Title, Type of Publication, Keywords/concept, Developmental domain, Particular area of the developmental domain and Authors' aim, findings and conclusions regarding the impact of VRTs. A total of 2721 studies were found published from 2010 to 2020. These studies included journal articles, conference proceedings, and reviews. In total, 2589 title and abstract studies were excluded and 32 were removed as duplicates. After screening, 112 studies were included in the eligibility assessment. Of these studies, 85 met the eligibility criteria and were included in the review (Fig. 2).

An excel spreadsheet was created which was the main guide that led to the classification of the results according to the developmental domain, i.e. physical, cognitive and psychosocial and their particular area, e.g. for the psychosocial domain, particular areas are the addiction, anxiety, emotional effects, internet gaming disorders, prosocial and social behaviour (Table 1).

Taking into account the above results to answer the research questions, we can remark the following:
RQ1 Regarding the potential risks of virtual reality (software and hardware) to children, the review identified 85 articles. Out of the 85 articles, 28 focused on the physical domain, while 38 related to the cognitive domain and 29 referred to the psychosocial domain. It is important to mention that some articles covered two domains. Thus, 3 articles were identified for both the cognitive and psychosocial domain, 2 articles for both the physical and the cognitive domain and 1 article that examined all 3 development domains. It was also often the case that the articles did not focus only on one area of the developmental domain but extended to 2, 3 or even 4 areas.

Concerning the sub-questions:

RQ1a Cybersickness, obesity, radiation, sleep disorders and visual symptoms are the most frequently identified concerns about children's physical development.

RQ1b The most frequently identified issues for children's cognitive development refer to attention, learning, general cognition and spatial cognition as well.

RQ1C For the psychosocial development of children, the concerns are mainly focused on addiction, anxiety, 
emotional effects, internet gaming disorders, prosocial and social behaviour.

The results of the studies included in the review are then presented in detail by developmental domain, highlighting both the researchers' agreements and disagreements.

\subsection{Physical development}

Physical development encompasses growth and changes in body and brain, senses, motor skills, health and wellness (Spielman et al. 2020). Regarding the impact of VRT and gaming on children physical development, the most common research fields are related to cybersickness, visual symptoms, obesity, radiation, sleep disorders, and cardio-metabolic deficiencies (Table 2). It is important to emphasize that issues related to physical development affect cognitive and psychosocial development and vice versa.

Cybersickness is a condition that indicates symptoms of nausea, disorientation and oculomotor during and/or after experiencing virtual environments in head-mounted displays, large screens, and curved screen systems (LaViola 2000; Nolin et al. 2016; Rebenitsch and Owen 2016). Nausea is referred to as general discomfort, stomach awareness, even vomiting. Disorientation symptoms include difficulty focusing, vertigo, and dizziness. Symptoms in the oculomotor system may cause fatigue, headache, and eyestrain. Between HMDs, desktop displays and large screens, HMDs present the highest amount of cybersickness (Rebenitsch and Owen 2016). Roettl and Terlutter (2018) analysed how an identical video game that is either played in a 2D, stereoscopic 3D or Head-Mounted-Display (HMD) VR version is experienced by the university students/players. Students reported higher levels of dizziness and motion-sickness in the VR game than in the 3D and 2D game.

As up-to-date evidence has shown that cybersickness symptoms persist for some time after leaving the VR without, however, long-term or permanent effects (Bruck and Watters 2009; Dużmańska et al. 2018), the greatest concern is focused on the potential impact on the visual system. Of particular interest are the effects of size, type, and weight of the devices used for VR games, such as laptops, large television screens, tablets, smartphones, and especially HMDs (Wang et al. 2020). More accurately, researches focus on visual placement, hygiene, and child safety standards. Worries are about VRTs impacts on the immature visuomotor system, adverse effects on accommodation, vergence, and stereoscopic vision, as well as visual-motor coordination (eye-hand coordination), i.e. matching or mismatching between the visual information and the hand movements (Gent 2016; Tychsen and Foeller 2020). Rechichi et al. (2017) conducted a cross-sectional study of possible video game vision syndrome and concluded that prolonged use of video games for $30 \mathrm{~min}$ or more a day by children up to 10 years of age may affect and compromise the development of their visual pathways. It is important to mention that most of the children did not complain of headaches while playing video games. Tychsen and Foeller (2020) designed research to find out the effects of immersive VR on the visual motor function of 50 children aged 4-10, postural stability, and motion sickness (via a 3D virtual reality game). Baseline testing was implemented before VR exposure and each VR session was followed by post-VR testing of binocular corrected distance visual acuity, refractive error, binocular eye alignment (strabismus), stereoacuity (stereoscopic acuity), and postural stability (imbalance). The results confirmed that (a) changes in heterophoria and near-point of accommodation were negligible, (b) the refractive error measurements disclosed no evidence of accommodative myopia or other refractive change and (c) the stereoacuity measures showed no degradation. Additionally, symptoms of eyestrain or nausea/motion sickness were minor. A significant issue was that children reported less negative effects on the same visual experience than adults exposed to the same VR. No matter how far away an object appears, the eyes remain focused on a fixed point, converging on something in the virtual distance, without having vergence-accommodation conflict (Gent 2016). The study of visual fatigue using HMDs and two-dimensional displays indicated that the findings were not significantly different between the two types of devices (Hirota et al. 2019). However, the vergence-accommodation conflict (VAC) remains a major issue in HMDs for VR (Kramida 2016). In 2018, the American Academy of Ophthalmology (2018) concluded that the increasing prevalence of myopia worldwide is associated with almost all activities performed close to eyes, not only screen-related works but also reading traditional books. Currently, the world is facing a global pandemic known as COVID-19 due to SARSCoV-2, and social distancing, schools' closures, isolation, and quarantine have been chosen to deal with its dispersion by most countries. Due to the pandemic, many children obligated to learn through digital virtual learning. Online learning increases digital screen time and therefore an increased risk of myopia onset and progression in children. However, myopia development appeared to be related only to reading, but not watching television, playing computer games or even studying (Wong et al. 2020).

Regarding the safety of HMDs, Tychsen and Foeller (2020) reported that long-term deleterious effects, eyestrain, head and/or neck discomfort, dizziness, and motion sickness/cybersickness were not mentioned by children while playing VR games. VR video game technology, on the other hand, has been used to detect and treat children amblyopia (in which visual acuity in one eye is poorer than the other), strabismus, and convergence insufficiency with promising results (Kelly et al. 2016; Greuter et al. 2020). VRTs have 


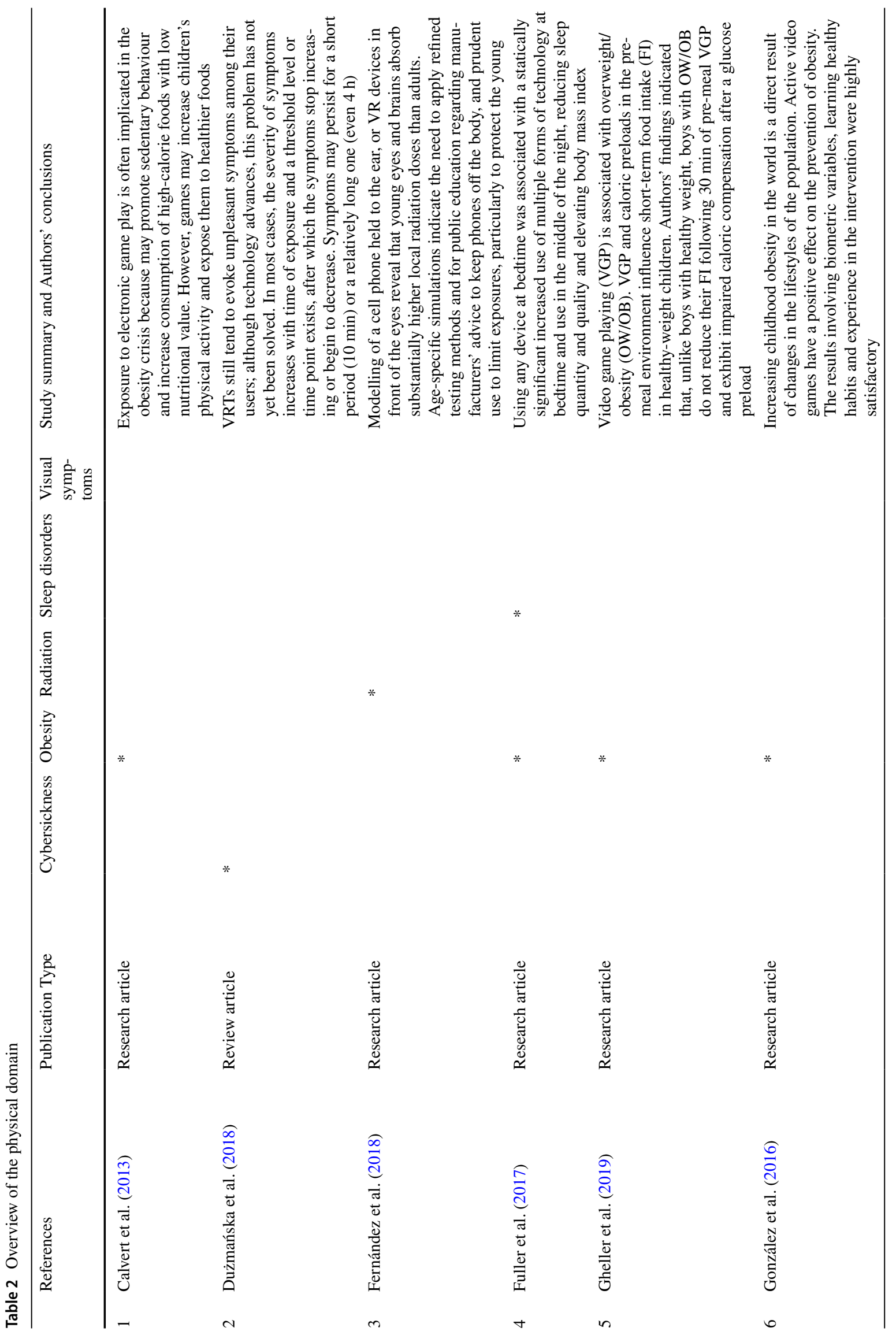




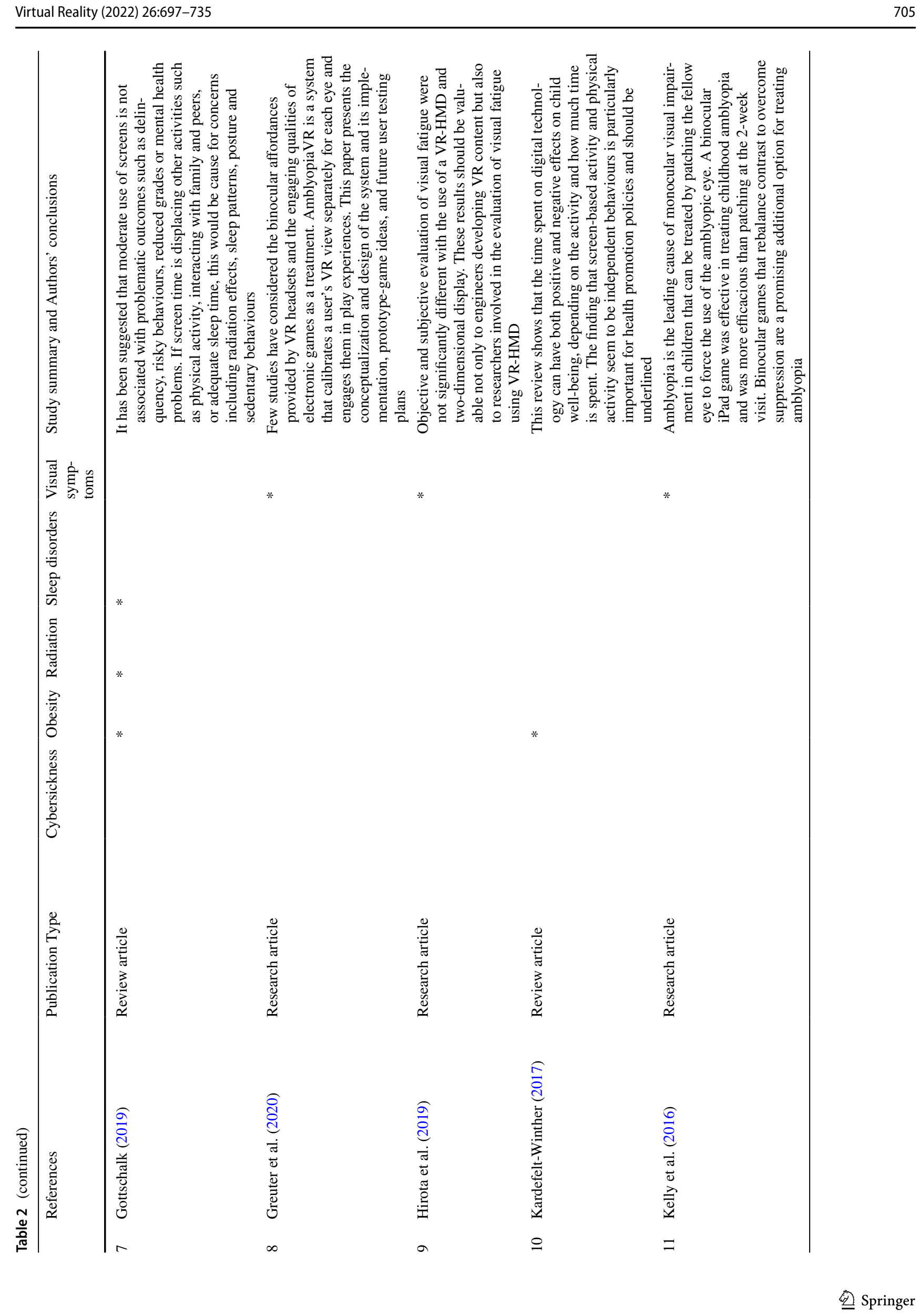




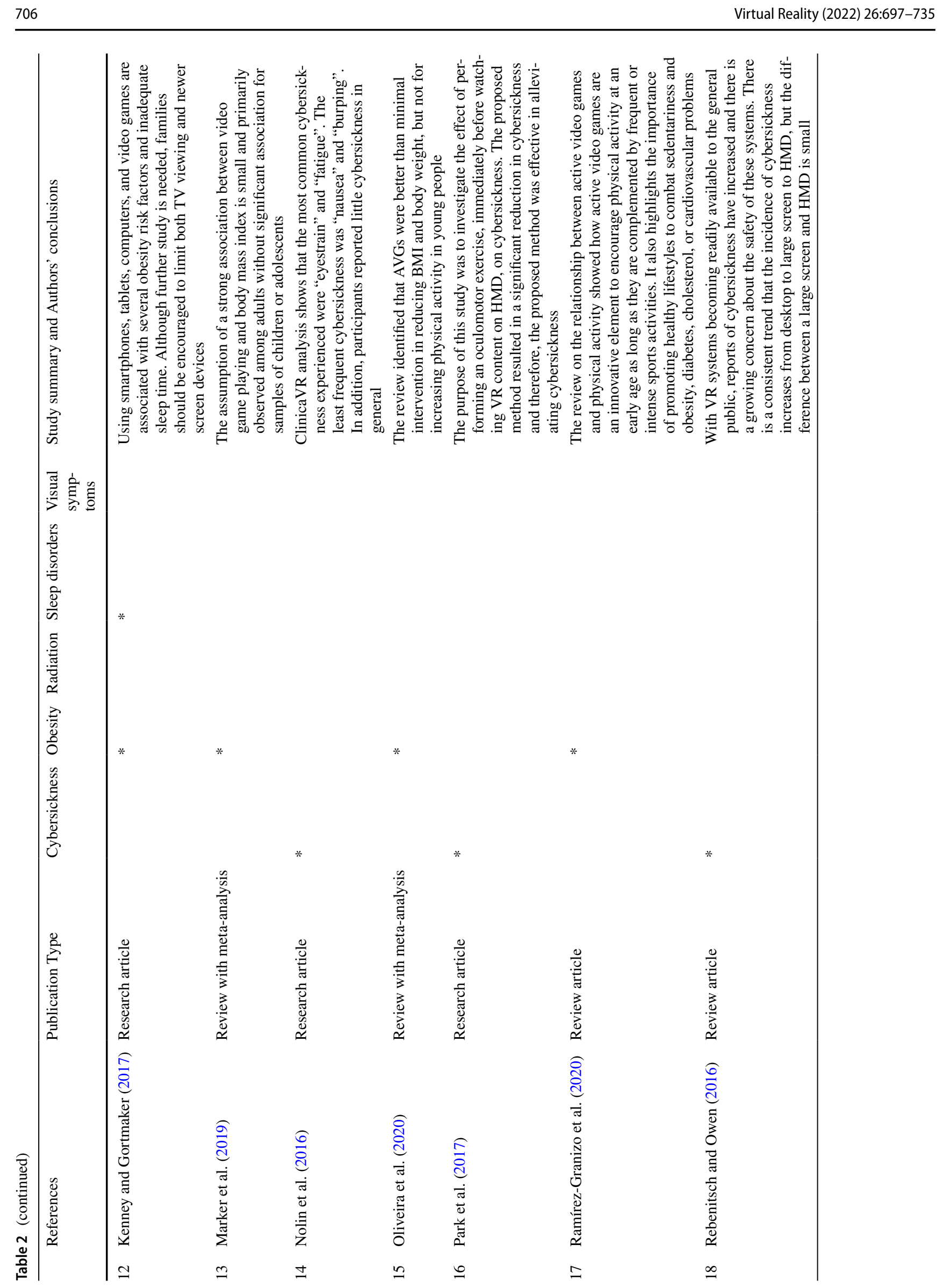

照 Springer 


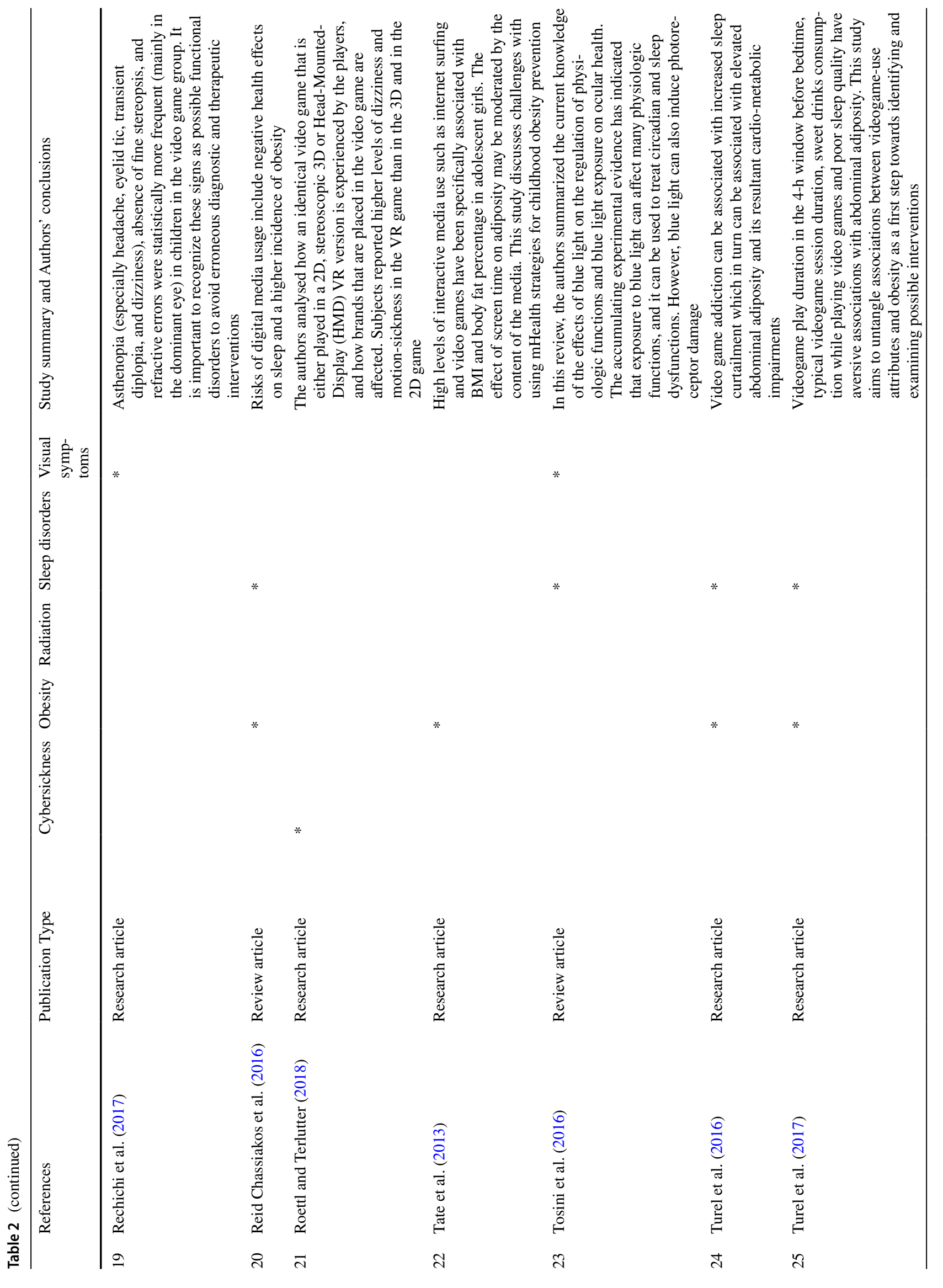




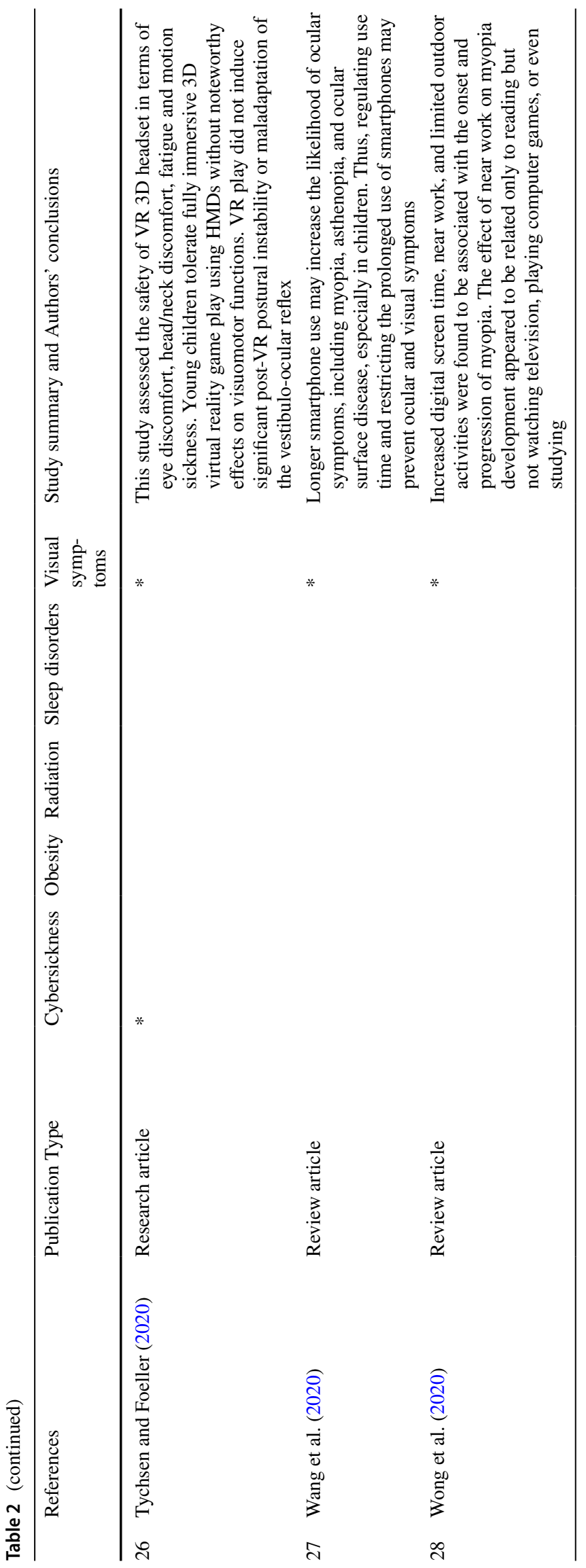


also been used therapeutically for eye-hand coordination in children with cerebral palsy or Down syndrome (Tychsen and Foeller 2020). Howarth (as cited in Gent 2016) noted that "only those with already weak eye movement and control are likely to experience adverse effects such as headaches and eyestrain". Howarth also added that these findings are good indicators for children who have similar symptoms, and parents should have their children's eyes checked. Therefore, HMDs can help identify existing problems. In contrast, the blue light emitted by the screens can induce photoreceptor damage (Tosini et al. 2016).

The problem of obesity is set in the broader context of the time spent on digital technology that distracts children from physical activity and is not just a matter of VR (Tate et al. 2013; Kardefelt-Winther 2017; Gottschalk 2019). As a wide range of video games are developed with VRTs, there is particular concern about their correlation with obesity risk factors (Kenney and Gortmaker 2017; Gheller et al. 2019). The feeling of getting "lost" in a fully immersive experience could lead to overeating, a sedentary (non-active) lifestyle and overweight. The correlation between video games and obesity is complex and indirect. Different gaming habits such as playing during bedtime and consumption of highcalorie sweet drinks and foods with low nutritional value during video game playing can be interconnected and ultimately related to childhood obesity and sedentary behaviour (Calvert et al. 2013; Kenney and Gortmaker 2017; Turel et al. 2017). However, the assumption of a strong association between video game playing and body mass index is small and primarily observed among adults without significant association for samples of children or adolescents (Tate et al. 2013; Marker et al. 2019). Contrariwise, video games, especially motor games and active video games or exergames, have been shown to have a positive effect on the prevention of obesity by promoting tips and training programs for adopting healthy lifestyles and eating habits (Calvert et al. 2013; González et al. 2016). Although active video games encourage physical activity at an early age (Ramírez-Granizo et al. 2020), it seems that they do not lead to increased physical activity in young people (Oliveira et al. 2020). Furthermore, obesity and sedentary lifestyle due to non-active video gaming habits may result in longterm cardio-metabolic deficiencies among adolescents and consequently could be a cause of physical and psychological problems, including low self-esteem (Turel et al. 2016; Cappuccio and Miller 2017). Likewise, Fuller et al. (2017) found a statistically significant association between bedtime technology use and elevated body mass index.

Regarding sleep disorders, they have been proven to be directly related to low secretion of melatonin, known as "sleep hormone" (Gottschalk 2019). Melatonin starts rising about $2 \mathrm{~h}$ before a natural bedtime and is more sensitive to light in children than in adults. Computers, smartphones, and tablets emit short wavelengths or blue light and thus have brighter screens. The use of these bright devices at night has been associated with reduced concentrations of melatonin and therefore may negatively affects sleep and the circadian system (Tosini et al. 2016). Reduced sleep duration could be the cause of obesity, and obesity could cause reduced sleep. Sleeping less would give children more time to eat and to engage in other sedentary activities like gaming, resulting in a vicious circle (Turel et al. 2016, 2017; Reid Chassiakos et al. 2016; Fuller et al. 2017; Kenney and Gortmaker 2017; Cappuccio and Miller 2017).

Beyond obesity and sleep disorders, an equally important issue is the risk of exposure to wireless devices such as VR devices, as young eyes and brains have been found to absorb significantly higher doses of local radiation than adults (American Academy of Pediatrics 2016a; Fernández et al. 2018). Given that the systematic use of wireless devices by children is a relatively recent phenomenon, the long-term health risks are unclear due to a lack of longitudinal research data, as the previous generation was not exposed to this type of radiation in childhood or adolescence (Gottschalk 2019).

\subsection{Cognitive development}

Cognitive development refers to the changes that occur in children's mental abilities including perception, attention, language, learning, and thinking (Shaffer and Kipp 2014). Nowadays, digital media have been integrated into everyday life and children spend a lot of time playing games on screens or with HMDs. Therefore, a reasonable question arises about games efficiency to improve or impair cognitive skills. In this context, the research focused on the potential of digital games, both Commercial-Off-the-Shelf (COTS) games and serious games (Abt 1975) (i.e. those that are primarily designed to improve learning outcomes in addition to entertainment) to develop cognitive skills such as working memory, attention and spatial cognition (Mayer 2019; Makransky et al. 2019; Kaimara et al. 2019a; Parong and Mayer 2020). Table 3 presents the reviewed studies focused on the cognitive domain. Serious games can promote learning with cognitive, behavioural and affective outcomes (Boyle et al. 2016). Checa and Bustillo (2020) provided recommendations for the improvement of serious games in immersive VR environments to the enhancement of both learning and training tasks. Numerous surveys offer evidence of positive learning outcomes resulting from the use of digital media in which users can consume and actively create content (Gee 2008; de Freitas and Liarokapis 2011; Girard et al. 2013; Granic et al. 2014; Reid Chassiakos et al. 2016; de Freitas 2018; Erhel and Jamet 2019; Fokides 2020) while some academics examine games more critically not only in terms of motivation but also concerning their discovery, constructivist and problem-based learning pedagogy, 
Table 3 Overview of the cognitive domain

\begin{tabular}{|c|c|c|c|c|c|c|}
\hline References & Publication Type & Attention & Learning & $\begin{array}{l}\text { Spatial } \\
\text { cogni- } \\
\text { tion }\end{array}$ & $\begin{array}{l}\text { General } \\
\text { cogni- } \\
\text { tion }\end{array}$ & Study summary and Authors' conclusions \\
\hline
\end{tabular}

$1 \quad$ Adjorlu et al. (2017)

Research article

$*$

2

Adjorlu and Serafin (2019)

Research article

3

Bennett et al. (2018)

$4 \quad$ Blume et al. (2017)

$5 \quad$ Boyle et al. (2016)

6

Chang et al. (2020)
Research article

Research article *
The authors present a study conducted to investigate the feasibility and effectiveness of VR applied to daily living skills (DLS) training of individuals diagnosed with Autism Spectrum Disorder (ASD). The study indicates some positive effects of a head-mounted display based VR simulation to train DLS. However, further research is needed to measure the long-term effects

The authors presented a study conducted to investigate the feasibility and effectiveness of VR for teaching money skills to adolescents diagnosed with Autism Spectrum Disorder (ASD). VR roleplay training illustrates some potentials and benefits in using VR as a mean to teach money skills. A pre- and post-VR training evaluation was conducted using real coins and bills

VR can provide robust assessment of cognitive spatial processing skills in individuals with visual impairment. Findings from the current work demonstrate a successful interaction between individuals with visual impairments and VR simulations in assessing high-level visual function

Generalization of acquired self-regulation skills from laboratory to real life is crucial for a transfer to everyday situations and is hypothesized to be facilitated via training using VR environments. As the authors argued, this was the first study investigating the efficacy of neurofeedback training for children with ADHD in a VR compared to a $2 \mathrm{D}$ environment

The current review focused on 143 papers that provided higher-quality evidence about the positive outcomes of games. The most frequently occurring outcome reported for games for learning was knowledge acquisition, while entertainment games addressed a broader range of affective, behaviour change, perceptual and cognitive and physiological outcomes

This study proposed a non-immersive VR guidance system combined with a two-tier strategy to help students learn geology knowledge. The two-tier test VR guidance system not only improved the students' learning achievement in natural science, but also enhanced their learning motivation, and help students answer questions and solve problems more effectively 
Table 3 (continued)

\begin{tabular}{|c|c|c|c|c|c|c|}
\hline References & Publication Type & Attention & Learning & $\begin{array}{l}\text { Spatial } \\
\text { cogni- } \\
\text { tion }\end{array}$ & $\begin{array}{l}\text { General } \\
\text { cogni- } \\
\text { tion }\end{array}$ & Study summary and Authors' conclusions \\
\hline
\end{tabular}

7 Checa and Bustillo (2020) Review article

8

Connors et al. (2014)

9

Dalgarno and Lee (2010)

Research article

Review article

10 De Freitas (2018)

11 Dixon et al. (2019)

12 Erhel and Jamet (2019)
Research article

*

The study aimed to identify the factual standards of the proposed solutions and the differences between training and learning applications. The study provided recommendations for the improvement of serious games in immersive VR-environments to the enhancement of both learning and training tasks

For individuals who are blind, navigating independently in an unfamiliar environment represents a considerable challenge. Virtual environments and gaming in the development of mental spatial representations can facilitate the transfer of spatial knowledge and further, can be used by individuals who are blind for navigation in real-world environments

This article explored the potential learning benefits of three-dimensional (3-D) virtual learning environments (VLEs). The authors identified a series of learning affordances: spatial knowledge representation, greater opportunities for experiential learning, increased motivation/engagement, improved contextualisation of learning and collaborative learning

To the question: are games effective learning tools, the answer from the research is overwhelmingly positive. Despite resistance to the adoption of game-based approaches in schools, colleges and universities, like online learning, it will be a matter of time before the cost benefits drive uptake widely and the full implication of the research is fully understood

Immersive VR environments may offer the advantages of both contrived and natural environment training settings, providing structure to create repeated learning opportunities in a safe and realistic environment. The current study evaluated the effectiveness of a VR safety skills training environment in teaching children with ASD to cross the street with very promising results The authors explored the relationship between goal specificity, flow experience and learning outcomes in educational computer games. A nonspecific goal, as opposed to a specifically defined goal, enhances comprehension, but not memorization and affects reading strategies. Also, they concluded a beneficial influence of flow experience on both memorization and comprehension 
Table 3 (continued)

References Publication Type Attention Learning $\begin{aligned} & \text { Spatial } \\
& \text { cogni- } \\
& \text { tion }\end{aligned}$\begin{tabular}{l}
$\begin{array}{l}\text { General Study summary and Authors' conclusions } \\
\text { cogni- } \\
\text { tion }\end{array}$ \\
\hline
\end{tabular}

13 Fokides and Chachlaki (2020) Research article

14 Fowler (2015)

15 Freina and Ott (2015)

16 Girard et al. (2013)

17 Granic et al. (2014)

18 Jeong et al. (2015)
Research article

Review article

Review article

Review article

Research article *
The study presented the results for a 3D multi-user VR for raising awareness of environmental issues. The target group was 326 students aged 10-12-years old divided into three groups according to taught material: (1) printed material, (2) webbased application, and (3) VR. The VR had a notable impact on students' attitudes towards seals protection compared to the other tools

The aim of this paper was to build upon Dalgarno and Lee's model of learning in three-dimensional (3-D) virtual learning environments (VLEs) and to extend their road map for further research in this area. The paper adopted a "design for learning" perspective and provided a combined framework to those designing learning activities in 3-D VLEs

This paper is a Review article of the advantages and potentials in the use of Immersive VR in Education (2013-2014). It examines the use of VR in general, and immersive VR in particular, for adult or university students training, and the possible advantages for children and some kinds of cognitive disabilities. The paper outlined strategies that could be carried out to verify these ideas

Computer-assisted learning is known to be an effective tool for improving learning in both adults and children. The objective of this research was to review the results of experimental studies designed to examine the effectiveness of games on players' learning and engagement. Games potentials illustrate why it is important to continue to study their effectiveness

Video games are a ubiquitous part of almost all children's and adolescents' lives. The authors summarized the research on the positive effects of playing video games, focusing on four main domains: cognitive (e.g. attention), motivational (e.g. resilience in the face of failure), emotional (e.g. mood management), and social (e.g. prosocial behaviour) benefits

This qualitative approach study aimed to understand the overall experiences of students using notebooks in class. Interview data were collected from 23 Korean college students at a Korean University. The results implied that appropriate methods of technology usage are needed and that the support of an instructor is essential to achieve fully beneficial use of notebooks in class 
Table 3 (continued)

$\begin{array}{lll}\text { References } & \text { Publication Type Attention Learning } \begin{array}{l}\text { Spatial } \\ \text { cogni- } \\ \text { tion }\end{array} & \begin{array}{l}\text { General Study summary and Authors' conclusions } \\ \text { cogni- } \\ \text { tion }\end{array}\end{array}$

19 Kaimara et al. (2019a, b) Research article

$*$

20 Kaimara et al. (2020a, b)

Research article

21 Kenny and Gunter (2011)

Research article

22 Kim et al. (2020)

23 Koops et al. (2016)

24 Lamb et al. (2018)
Review article
Serious games (SGS) are gaining an everincreasing interest of many scholars regarding learning. This quantitative research focused on students' characteristics and factors that affect learning experience when playing 2D or 3D SGs. The results revealed that other learners' skills beyond demographics such as self-regulation, spatial cognition and mental rotation should be considered

The main objective focused on the correlation of the University students' views that were sharing common characteristics, like gender, information and communication technology skills, game playing experience, and specific scientific background with factors that related to the gameplay as well as the learning effectiveness

Video games are one of the fastest-growing elements of informal, virtual learning. In this article, the authors presented a design and evaluation rubric that appears to overcome many of the shortcomings in educational games currently on the market

In this paper, the authors introduced and demonstrated the benefits of a new type of treatment, namely, an eye-contact game that successfully exploits mixed reality technology with head-mounted display. ADHD children, after participating in the treatment sessions, the omission/commission errors which were evaluated in an attention test decreased significantly

Research article $\quad * \quad *$

Computer games, based on physics simulations, have been utilized to provide an alternative learning tool. In this research, the authors investigated if commercial entertainment games can be used to overcome misconceptions of Newton's laws of motion. They concluded that self-designed educational games induce a significantly higher learning gain than commercial entertainment game

The purpose of this meta-analysis was to characterize and compare outcomes related to serious educational games, serious games, and educational simulations as they are presented in the educational literature. The examined studies suggest that ES, SGs, and SEGs do not differ in a statistically significant way when compared to traditional instruction but do differ from each other 
Table 3 (continued)

References $\quad \begin{gathered}\text { Publication Type Attention Learning } \\ \begin{array}{l}\text { Spatial } \\ \text { cogni- } \\ \text { tion }\end{array}\end{gathered}$

25 Makransky et al. (2019) Research article

*

The objective was to compare the effectiveness of an immersive VR simulation, a desktop VR simulation, and a conventional text-based manual for delivering laboratory safety training. Significant differences were observed favouring the immersive and desktop VR compared to the text on solving problems, perceived enjoyment, intrinsic motivation and self-efficacy
The aim of this study was to examine the safety and usability of these systems for children with ASD. Children with ASD indicated that HMDs improve spatial participants preferred using HMDs over monitor-displayed video. These findings provided preliminary evidence to support the safety and usability of HMDs-VR for children with ASD

Visionaries offer strong claims for the educational benefits of computer games, but there is a need to test those claims with rigorous scientific research and ground them in evidence-based theories of how people learn. Future research is needed to pinpoint the cognitive, motivational, affective, and social processes that underlie learning with educational computer games

The authors hypothesised that it is possible to design VR learning activities that can help students to develop their spatial ability. To prove their hypothesis, they had conducted an experiment consisting of training the students using an on-purpose VR learning application. The conclusion is that VR learning activities have shown to improve spatial ability

The authors sought to place children with ASD examining the potential of VR HMDs used in classrooms. Students identified several potential usages for HMDs such as relaxing/feeling calm, being able to explore somewhere virtually before visiting the real place and developing learning opportunities. HMDs were reported as enjoyable, physically and visually comfortable, easy to use

The majority of neuropsychological studies using virtual reality have dealt with adults while studies with children and adolescents are relatively scarce. Of the few studies which have been conducted with children, data were mostly generated using the Virtual Classroom Clinica. ClinicaVR is recommended as an assessment tool for selective and sustained attention presence and realism and $74 \%$ of 35 
Table 3 (continued)

References Publication Type Attention Learning Spatial General Study summary and Authors' conclusions
cogni- cognition tion

31 Palaus et al. (2017)

32 Parong and Mayer (2020)

Research article *

33 Passig et al. (2016)
36 Spence and Feng (2010) Review article * * *
* $\quad * \quad$ The authors aimed to understand the relationship between the use of video games and their neural correlates. Despite the heterogeneity of the field of study, it has been possible to establish a series of links between the neural and cognitive aspects, particularly regarding attention, cognitive control, visuospatial skills, cognitive workload, and reward processing

The goal of the study was to examine the effects of playing an immersive VR game that included a collection of gamified cognitive tasks, on specific components of cognition, including perceptual attention, mental rotation, working memory, visualization, visual field of view, and visual processing speed. No evidence that brain training games improve specific components of cognition

The main objective of this research was to study the degree to which the learning process in a dynamic assessment procedure using a computerized 3D Immersive Virtual Reality (3D IVR) framework contributes to the cognitive modifiability of children. The findings indicate that teaching in a 3D IVR environment contributed to the children's cognitive modifiability

The use of digital media has evidence-based benefits including early learning, exposure to new ideas and knowledge, and increased opportunities for social contact and support. Also, risks of such media include negative effects on attention. To promote wellness in children and adolescents, it is important to set an appropriate balance between screen time/online time and other activities

The authors analysed how an identical video game that is either played in a $2 \mathrm{D}$, stereoscopic 3D or Head-Mounted-Display (HMD) VR version is experienced by the players, and how brands that are placed in the video game are affected. A post hoc study shows that cognitive load was highest in the VR game and lowest in the 3D game

The authors reviewed studies that investigate the ability of video games to modify processes in spatial cognition. Several experiments have shown that playing action games induces changes in several sensory, perceptual, and attentional abilities that are important for many tasks in spatial cognition. Action video games have a beneficial effect on complex tasks such as mental rotation 
Table 3 (continued)

\begin{tabular}{|c|c|c|c|c|c|c|c|}
\hline & References & Publication Type & Attention & Learning & $\begin{array}{l}\text { Spatial } \\
\text { cogni- } \\
\text { tion }\end{array}$ & $\begin{array}{l}\text { General } \\
\text { cogni- } \\
\text { tion }\end{array}$ & Study summary and Authors' conclusions \\
\hline 37 & Weerdmeester et al. (2016) & Research article & $*$ & & & & $\begin{array}{l}\text { The study assessed the feasibility and effec- } \\
\text { tiveness of a full-body-driven intervention } \\
\text { videogame targeted at decreasing ADHD } \\
\text { symptoms, specifically inattention, hyper- } \\
\text { activity, impulsivity, and motor deficiency. } \\
\text { Children who played the game improved in } \\
\text { several areas with only a short amount of } \\
\text { gameplay (1.5 h in total), and their satisfac- } \\
\text { tion with the game was high }\end{array}$ \\
\hline 38 & Zaharias et al. (2017) & Research article & & $*$ & $*$ & & $\begin{array}{l}\text { In this study, two versions ( } 2 \mathrm{D} \text { and } 3 \mathrm{D} \text { ) of } \\
\text { a serious educational game on geography, } \\
\text { were developed for elementary schools. } \\
\text { Both versions had a positive impact on } \\
\text { learning. 2D version had a greater impact } \\
\text { compared to 3D, regarding learning, while } \\
\text { the 3D version had a greater impact on } \\
\text { motivation to learn and user experience }\end{array}$ \\
\hline
\end{tabular}

and performance-based measures (Clark et al. 2010; Fowler 2015; Chang et al. 2020). Indeed, games gather powerful structural elements (i.e. rules, goals and objectives, feedback, challenges, interaction and story) (Prensky 2007) that attract, engage, and motivate children. However, these elements are not enough for a game to be considered an educational one (Gunter et al. 2006; Kenny and Gunter 2011). Palaus et al. (2017) argued that despite the heterogeneity of the field, it has been possible to establish a series of links between the neural and cognitive aspects, particularly regarding attention, cognitive control, visuospatial skills, cognitive workload, and reward processing.

In recent years, there has been a change in video game development technology and instead of two-dimensional (2D) VE, video games can be played in a three-dimensional (3D) VE or using HMDs (Freina and Ott 2015; Roettl and Terlutter 2018). 2D games display less immersion than 3D ones, which become even more realistic when played with special equipment, such as HMDs (Roettl and Terlutter 2018). Researches on perceived learning effectiveness depending on the type of $2 \mathrm{D}$ or $3 \mathrm{D}$ game have revealed that 2D games are considered more effective compared to 3D (Koops et al. 2016; Zaharias et al. 2017; Kaimara et al. 2020a). These findings are consistent with Mayer's conclusions (Mayer 2019). Students learn better when games are rendered on a desktop screen than in immersive VR perhaps due to distraction. Chang et al. (2020) similarly assumed that their non-immersive VR guidance system not only improved students' learning achievement in natural science, but also enhanced their learning motivation, and help them answer questions and solve problems more effectively. One possible explanation may be related to the fact that in 3D-model players need to process more information and consequently greater working memory resources are required. Therefore game navigation demands more cognitive resources, leaving fewer resources for learning objectives (Roettl and Terlutter 2018; Kaimara et al. 2020a). Furthermore, Mayer (2019) claimed that realism is not a promising game feature when the goal is to improve learning outcomes. On the contrary, Lamb et al. (2018) concluded that 3D simulations and games are more effective in changing student outcomes and these results derive from perceived realism and consequential engagement. Fokides and Chachlaki (2020) came to the same conclusion investigating the effectiveness of a 3D multi-user VR environment for raising environmental awareness in children. 326 students aged 10-12-years old divided into three groups according to the taught material: (1) printed material, (2) web-based application, and (3) VR. The VR had a notable impact on students' attitudes towards seals protection compared to the other tools. Similarly, Passig et al. (2016) indicated that teaching in a 3D VR environment contributed to the children's cognitive modifiability. Dalgarno and Lee (2010) identified a series of learning affordances of 3-D virtual environments, i.e. spatial knowledge representation, greater opportunities for experiential learning, increased motivation/engagement, improved contextualisation of learning and collaborative learning. Correspondingly, Parong and Mayer (2020) researched the effects of playing immersive VR games on specific components of cognition, i.e. perceptual attention, mental rotation, working memory, visualization, visual field of view, and visual processing speed. Arguing that immersion could increase learner's feeling of presence, motivation, and attention in a virtual world, their research results do not provide strong evidence that playing such games affects specific components of cognition. Mayer (2019) came to 
the same conclusion by investigating the effect of so-called brain training games, which contain a series of mini-games. Their ineffectiveness may be due to the lack of focus on a single cognitive ability. However, given indications of gender differences in spatial cognition and mental rotation, females can improve spatial skills playing 3D games (Peters et al. 2006; Moreau et al. 2010; Spence and Feng 2010). Moreover, VR can robust assessment of cognitive spatial processing skills in typically developing students and individuals with visual impairment and Autism Spectrum Disorders (ASD) (Connors et al. 2014; Bennett et al. 2018; Molina-Carmona et al. 2018; Malihi et al. 2020). Adjorlu and colleagues (Adjorlu et al. 2017; Adjorlu and Serafin 2019; Adjorlu and Serafin 2020) have conducted a series of studies on the use of VR applications and HMDS by children with ASD. They focused mainly on daily skills training, such as shopping in supermarkets, street-crossing skills and managing money and social skills. The conclusions they have reached from their assessments are very promising for learning outcomes, reduction of disruptive behaviour and social anxiety, and collaborative learning in inclusive classrooms. Additionally, Newbutt et al. (2020) reported that students with ASD found HMDs enjoyable, physically and visually comfortable, and easy to use. Parong and Mayer (2020) also assumed that utilising video games could enhance cognitive skills and improve everyday and academic skills.

As mentioned, imagination is one of the "I" dimensions of VEs (Burdea and Coiffet 2003). Thus, VR has the potential to affect children's imagination, empathy, experiential and embodied learning. Consequently, imagination may prompt confusion between real events and fiction and may cause sensory and cognitive overload (Sobel 2019). Children are less able to distinguish what is real from what is imaginary compared to adults, may confuse VR experiences with those that occur in the physical world and identify with avatars (Segovia and Bailenson 2009; Bailey and Bailenson 2017). Standen and Brown (2006) referred to an example related to a car accident. Being hit by a virtual car cannot convey exactly what happens when being hit by a real car. Through VR-Educational Technologies are provided opportunities for experiential active learning in a safe, controlled, repeatable, and adjustable environment, reducing the risks of real-life, allowing students to learn from their mistakes without suffering effects produced by the real world and at the same time encouraging and promoting participation (Newbutt et al. 2017; Dixon et al. 2019). However, in cases where the VR applications are chosen as a method to teach children with neurodevelopmental disabilities to reduce the danger of in-vivo instructions, there is a risk that the learners may not fully understand the real danger in the real world and therefore the involvement of the educator becomes crucial.
Thus, adults should help children to make the connection and to rate the differences between real-world and VEs. It is also important to note that the fiction-real relationship permeates almost all digital and non-digital media, books, fairy tales with fantastic heroes, such as Tooth Fairy and celebrity entities such as Santa Claus, movies, and comics on television and in cinema, and is not solely related to VR technology content. Furthermore, it should be emphasized that confusion between reality and non-reality is a children developmental stage, which is directly related to the metacognitive limitations, the Theory of Mind and pretence, fields that have been extensively explored by pioneers such as Piaget, Flavell, Green, Wellman, etc. (Woolley and Ghossainy 2013). Therefore, VR because primarily relies on realism, immersion, and presence can effect children, these result may last and adults' role in facilitating the disconnection of real from non-real is decisive.

Studies focusing on attention when using mobile devices in the classroom are associated with distraction (Reid Chassiakos et al. 2016). However, the negative impact of devices often occurs when laptops and tablets are permitted without limits and distraction is due to the uncontrolled Internet use during teaching (communicate via messaging, having fun and pretending to be working on something related to the lesson, etc.) (Jeong et al. 2015). Attention and distraction in VEs can be studied by observing individuals with Attention Deficit Hyperactivity Disorder (ADHD) (American Psychiatric Association 2013). ADHD is a neurodevelopment disorder characterized by inattention, disorganization, and/or hyperactivityimpulsivity directly associated with limited attention and distraction, and particular research is needed to determine whether or not technology enhances the manifestations of the disorder. While cognitive overload due to technology and multitasking is associated with poorer attention spans, the link between ADHD and technology has not yet been proven. The increased Internet use and media sources produce abnormal patterns of behaviour which may reflect symptoms similar to ADHD-like behaviours (Steve and Grubb 2018). Contrariwise, promising results were found early enough regarding the rehabilitation of inattention and impulsiveness through VR (Cho et al. 2004; Kim et al. 2020). Cho et al. studied twenty-eight participants aged 14-18 years who had learning difficulties and presented inattentive, impulsive, hyperactive, and distracted behaviour without official ADHD diagnosis and found that participants were reducing the level of inattention and impulsiveness through the immersive VR interventions. Recent results of research data conclude that cutting-edge technologies such as VR, augmented reality (AR), mixed reality (MR), mobile devices, and VR games provide opportunities for ADHD children treatment by reducing their symptoms (Weerdmeester et al. 2016; 
Table 4 General overview of psychosocial domain

\begin{tabular}{|c|c|c|c|c|c|c|c|}
\hline References & Publication type & Addiction & Anxiety & $\begin{array}{l}\text { Emo- } \\
\text { tional } \\
\text { effects }\end{array}$ & IGI & $\begin{array}{l}\text { Prosocial/ } \\
\text { social behav- } \\
\text { iour }\end{array}$ & $\begin{array}{l}\text { Study summary and } \\
\text { Authors' conclusions }\end{array}$ \\
\hline
\end{tabular}

1 Adjorlu and Serafin (2019) Research article

$*$

2 Carbonell (2017)

Review article

$3 \quad$ Festl et al. (2013)

Research article
Review article
The authors' presented a study investigating the feasibility of using VR to reduce disruptive classroom behaviour of a child diagnosed with Autism Spectrum Disorder (ASD). The study provides guidelines to educators and designers who plan to develop applications for educating children with ASD regarding social skills

The author discussed the confusion in DSM-5 diagnosis for Internet Gaming Disorder due to the weak criteria. The release of new genres of video games, VR, online video gaming, different video game mechanics and social structures, and the emergence of smartphones as the main platform are some of the new challenges for scholars

Playing digital games has been associated with forms of addictive behaviour. Following Gaming Addiction Short Scale (GAS) criteria, addiction is currently not a widespread phenomenon among adolescents and adults in Germany. GAS scores are associated with intensive use and certain problematic aspects of individuals' personalities and social lives

The authors summarized the research on the positive effects of playing video games, focusing on four main domains: cognitive, motivational, emotional, and social. They proposed some candidate mechanisms by which playing video games may foster real-world psychosocial benefits 
Table 4 (continued)

\begin{tabular}{lllll}
\hline References & Publication type & Addiction Anxiety $\begin{array}{l}\text { Emo- } \\
\text { tional } \\
\text { effects }\end{array}$ & $\begin{array}{l}\text { IGD Prosocial/ } \\
\text { social behav- Authors' conclusions } \\
\text { iour }\end{array}$ \\
\hline
\end{tabular}

5 Kaimara et al. (2020a, b) Review article

$*$

*

The author's main objective was to research braincomputer interfaces (BCI) concrete components and potential advances as well as depict potential limitations while using technological devices. Within this context, requirements, advantages, possible addiction risks, and boundaries regarding the specifications for $\mathrm{BCI}$ and technology are discussed

Videogame playing was associated with prosocial behaviour, life satisfaction, and lower levels of conduct, emotional and peer problems, and hyperactivity. The popular scientific claim that time spent on digital technology could make children addicted is a misrepresentation of existing knowledge

"Internet addiction" has been criticized for its lack of specificity given the heterogeneity of potentially problematic behaviours. Internet addiction and Internet Gaming Disorder (IGD) are not the same, and distinguishing between the two is conceptually meaningful. The DSM-5 has caused more confusion than clarity regarding the disorder

The authors designed an interactive scenario intended to elicit low to moderate amounts of negative emotion, wherein participants played out the scenario in either VR (using the HTC Vive) or on a laptop computer. VR gameplay has the potential to elicit strong negative emotional responses that could be harmful to users if not managed properly 
Table 4 (continued)

\begin{tabular}{|c|c|c|c|c|c|c|c|c|}
\hline & References & Publication type & Addiction & Anxiety & $\begin{array}{l}\text { Emo- } \\
\text { tional } \\
\text { effects }\end{array}$ & IGD & $\begin{array}{l}\text { Prosocial/ } \\
\text { social behav- } \\
\text { iour }\end{array}$ & $\begin{array}{l}\text { Study summary and } \\
\text { Authors' conclusions }\end{array}$ \\
\hline 9 & Lobel et al (2017) & Research article & & & $*$ & & $*$ & $\begin{array}{l}\text { The effects of games on } \\
\text { children's psychosocial } \\
\text { development: Gaming } \\
\text { at time were related to } \\
\text { increases in emotion } \\
\text { problems and decreases } \\
\text { in social behaviour, for } \\
\text { children involved in high- } \\
\text { frequency competitive } \\
\text { gaming. Neither violent } \\
\text { games were associated } \\
\text { with psychosocial changes } \\
\text { nor cooperative games } \\
\text { with changes in prosocial } \\
\text { behaviour }\end{array}$ \\
\hline 10 & $\begin{array}{l}\text { Madary and Metzinger } \\
\text { (2016) }\end{array}$ & Review article & $*$ & & & $*$ & & $\begin{array}{l}\text { The goal of this article was } \\
\text { to present a first list of } \\
\text { ethical concerns that may } \\
\text { arise from research and } \\
\text { personal use of VR and } \\
\text { related technology and } \\
\text { to offer concrete recom- } \\
\text { mendations for minimizing } \\
\text { those risks. The neuro- } \\
\text { physiological underpin- } \\
\text { nings of VR addiction may } \\
\text { differ from that of internet } \\
\text { use disorder }\end{array}$ \\
\hline 11 & Malihi et al (2020) & Research article & & $*$ & & & & $\begin{array}{l}\text { The aim of this study was } \\
\text { to examine the safety and } \\
\text { usability of these systems } \\
\text { for children with ASD. } \\
\text { The authors argued that } \\
\text { levels of anxiety and nega- } \\
\text { tive effects experienced by } \\
\text { children with ASD while } \\
\text { wearing HMDs or watch- } \\
\text { ing a monitor-displayed } \\
\text { video were not signifi- } \\
\text { cantly different }\end{array}$ \\
\hline 12 & Männikkö et al. (2015) & Research article & $*$ & & & & & $\begin{array}{l}\text { The aim of this study was } \\
\text { to identify problematic } \\
\text { gaming behaviour among } \\
\text { Finnish adolescents and } \\
\text { young adults, and evaluate } \\
\text { its connection to a variety } \\
\text { of psychological, social, } \\
\text { and physical health symp- } \\
\text { toms. Problematic gaming } \\
\text { behaviour was found to } \\
\text { relate to psychological and } \\
\text { health problems, namely } \\
\text { depression and anxiety } \\
\text { symptoms }\end{array}$ \\
\hline
\end{tabular}


Table 4 (continued)

\begin{tabular}{|c|c|c|c|c|c|c|c|}
\hline References & Publication type & Addiction & Anxiety & $\begin{array}{l}\text { Emo- } \\
\text { tional } \\
\text { effects }\end{array}$ & IGD & $\begin{array}{l}\text { Prosocial/ } \\
\text { social behav- } \\
\text { iour }\end{array}$ & $\begin{array}{l}\text { Study summary and } \\
\text { Authors' conclusions }\end{array}$ \\
\hline
\end{tabular}

13 Mesa-Gresa et al (2018) Review article

VR has emerged as an effective tool for intervention in the health field and treatment for individuals with ASD. The clinical focus of most of the reviewed studies was on emotional and/or social skills, including emotion recognition, collaboration, and social interaction tasks

The authors sought to place children with ASD examining the potential of VR HMDs used in classrooms and suggested that low-tech options such as smartphone-based HMDs could be a suitable tool for relaxing, exploring an environment just before visiting the real world. HMDs were reported by children as enjoyable, physically and visually

15 Newbutt et al. (2017) Review article

16 Palaus et al (2017)
Review article comfortable

This review was focused on the potentially useful application of VRTs to train and support people with an ASD in developing life-skills (i.e. social skills, job skills, independent living skills) and where there has been successful implementation in applied contexts. The authors also discussed the ethical approaches in using HMDs with this population

The authors aimed to understand the relationship between the use of video games and their neural correlates. Regarding addiction, the role of the reward system is always present when we talk about VGs, due to the way they are designed 
Table 4 (continued)

\begin{tabular}{ccccc}
\hline References & Publication type & Addiction Anxiety & $\begin{array}{l}\text { Emo- } \\
\text { tional } \\
\text { effects }\end{array}$ & $\begin{array}{l}\text { IGD Prosocial/ } \\
\text { social behav- Authors' conclusions } \\
\text { iour }\end{array}$ \\
\hline
\end{tabular}

17 Pallavicini and Pepe Research article

*
(2020) iour immersive technologies, especially virtual reality, into the gaming market, has dramatically altered the traditional concept of video games. The main principle findings of this study are as follows: VR video games appear to be effective tools to elicit positive emotions and to decrease negative emotions and state anxiety in individuals

The authors reviewed the scientific literature on IGD to provide an overview focusing on definitions, symptoms, prevalence, and aetiology. Developing IGD requires several interacting internal factors such as deficient self, mood and reward regulation, problems of decision-making, and external factors such as deficient family background and social skills

This study explored how time spent playing electronic games accounts for significant variation in the positive and negative psychosocial adjustment of children. The low engagement was associated with higher life satisfaction and prosocial behaviour and lower externalizing and internalizing problems, the opposite was found for high levels of play (2016)

Digital media use has evidence-based benefits including opportunities for social contact, support and access to health information. Risks are a higher incidence of depression, exposure to inaccurate/ unsafe content and contacts and compromised privacy. American Academy of Pediatrics Family Media Use Plan is recommended 
Table 4 (continued)

\begin{tabular}{|c|c|c|c|c|c|c|c|}
\hline References & Publication type & Addiction & Anxiety & $\begin{array}{l}\text { Emo- } \\
\text { tional } \\
\text { effects }\end{array}$ & IGD & $\begin{array}{l}\text { Prosocial/ } \\
\text { social behav- } \\
\text { iour }\end{array}$ & $\begin{array}{l}\text { Study summary and } \\
\text { Authors' conclusions }\end{array}$ \\
\hline
\end{tabular}

21 Rossi et al. (2018) Research article

$*$

22 Schneider et al. (2017)

Review article

The authors proposed the use of VR Games in the context of sensory processing disorders treatment (SPD). SPD often co-occurs with other disorders, e.g. ASD or ADHD Therapists reported that in general, the game had a positive effect on their treatments also reported signs of relaxation, increased concentration and changes in behaviour

Familial influences are known to affect the likelihood of an adolescent becoming a problem gamer. This systematic review examined some of the key findings in empirical research on family factors related to adolescent problem gaming. Familyrelated factors included parent status, parent-child relationship, parental influence on gaming and family environment

Internet Addiction (IA) symptoms in adolescents were investigated longitudinally. More hostile adolescents continue to present higher IA symptom severity, the relationship of MMORPG and IA symptoms holds over time and is similar to other forms of addictions, and the effect of MMORPG may differentiate between individual and classroom level

This study reviewed of ADHD to ascertain why its prevalence continues to rise in American society. Children at-risk for IA tend to fit some of the criteria for ADHD. Increased rates of ADHD is based on a linkage of events created by a lack of parent-child interactions that lead to an increase technology use which develops behaviours that mimic ADHD-like traits 
Table 4 (continued)

\begin{tabular}{|c|c|c|c|c|c|c|c|}
\hline References & Publication type & Addiction & Anxiety & $\begin{array}{l}\text { Emo- } \\
\text { tional } \\
\text { effects }\end{array}$ & IGD & $\begin{array}{l}\text { Prosocial/ } \\
\text { social behav- } \\
\text { iour }\end{array}$ & $\begin{array}{l}\text { Study summary and } \\
\text { Authors' conclusions }\end{array}$ \\
\hline
\end{tabular}
was to examine possible associations among growing problems in adolescents, as a means to point to plausible interventions. Videogame addiction among adolescents was negatively associated with sleep duration. Interventions aimed at problematic video-gaming could improve adolescents' longterm cardio-metabolic health

Adolescents with IGD have shown an increased functional connectivity of several executive control brain regions that may related to comorbidity with ADHD and depression. The evidence supports the behavioural addiction model of IGD by showing structural and functional changes in the mechanisms of reward and craving (but not withdrawal) in IGD

27 Weinstein and Lejoyeux (2020)

28 Weiss et al. (2011)
Review article

Review article
This review summarized studies on the neurobiological correlates of IGD and addictive internet use in adolescents and young adults. Brain imaging has shown that IGD shares neurobiological alterations that are typical for other addictions. Comorbidity studies indicate that executive control networks in ADHD may increase the susceptibility to develop IGD

The objective of this article was to review the research on ADHD as a risk factor for Internet addiction and gaming, its complications, and what research and methodological questions remain to be addressed. Internet and offline gaming overuse and addiction are serious concerns for ADHD youth 
Table 4 (continued)

\begin{tabular}{|c|c|c|c|c|c|c|c|c|}
\hline & References & Publication type & Addiction & Anxiety & $\begin{array}{l}\text { Emo- } \\
\text { tional } \\
\text { effects }\end{array}$ & IGD & $\begin{array}{l}\text { Prosocial/ } \\
\text { social behav- } \\
\text { iour }\end{array}$ & $\begin{array}{l}\text { Study summary and } \\
\text { Authors' conclusions }\end{array}$ \\
\hline 29 & Wichstrøm et al. (2019) & Research article & & & & $*$ & $*$ & $\begin{array}{l}\text { DSM-5-defined IGD is } \\
\text { already present in some } \\
\text { 10-year-olds, with a strong } \\
\text { male preponderance. } \\
\text { Symptoms of IGD are only } \\
\text { marginally associated with } \\
\text { symptoms of other psy- } \\
\text { chiatric disorders and only } \\
\text { predicted by social skills } \\
\text { and emotion regulation } \\
\text { deficits. Low social com- } \\
\text { petence and poor emotion } \\
\text { regulation skills predict } \\
\text { more IGD-symptoms }\end{array}$ \\
\hline
\end{tabular}

Wang and Yu 2018; Kim et al. 2020). VR systems are also recommended as an assessment tool for selective and sustained attention (Nolin et al. 2016). Besides, training in 3D VEs is expected to improve generalization of acquired self-regulation skills, executive functions and school performance of students with ADHD (Blume et al. 2017).

\subsection{Psychosocial development}

Psychosocial development includes emotions, personality, and interpersonal relationships (i.e. it is related to both psychological and social development). The most common worries are about addiction, anxiety, emotional behaviour, prosocial behaviour, and social skills/isolation (Table 4). It is worth noting that most research on the impact of VR on children, both psychologically and socially, was conducted through video games. Scientific research into the repercussions of VR is related to a brief period of immersion of a few minutes rather than hours (Madary and Metzinger 2016). Hence, given that in real life children are exposed to VRTs and playing games for more than a few minutes, studies should also focus on their effect on children's psychological development, incorporating results from psychology and neurosciences, because younger users are not yet psychologically and neurophysiologically fully developed. Several possible risks are associated with long-term immersion such as addiction, manipulation of agency, unnoticed psychological change, mental illness, e.g. depersonalization/ derealization disorder, and lack of "authenticity" (Madary and Metzinger 2016). A literature review revealed a correlation between the Internet, VR and gaming with possible psychological and psychiatric disorders. However, it remains unclear whether Internet use itself is the causal factor for increasing symptoms and impairment or simply a reflection of underlying difficulties (Weiss et al. 2011; Kuss et al.
2017; Steve and Grubb 2018; Paulus et al. 2018; Kaimara et al. 2020b).

As immersive VR employs HMDs, one research field is about their safety, usability, acceptability, and impact on all children, including those with autism (Newbutt et al. 2017, 2020; Malihi et al. 2020). It was decided to study their association to anxiety and possible effects on people with ASD, given that anxiety has been proven to be one of the most common co-occurring psychiatric disorders in people with ASD (Vasa and Mazurek 2015). In a study of twenty-nine individuals with ASD, regarding the influence of VR HMDs, Newbutt et al. (2017) found no evidence of an anxiety-provoking situation and sensory issues but rather a "like/dislike" feedback. As the participants wore an HMD for the first time in their lives, this finding is promising given that people with ASD resist new experiences and usually have sensory processing disorders (e.g. lack of attention, tactile defensiveness/sensitivity, visual/auditory sensitivity, gravitational insecurity) (Ayres and Tickle 1980; Roley et al. 2007; Davies and Gavin 2007). An equally important finding is that participants reported high spatial presence, engagement, and ecological validity within the VEs. Most of the VR interventions are focused on the improvement of daily living, social, and emotional skills with scenarios that facilitate the training of flexibility, identity, construction of social norms and emotional recognition and the enhancement of collaboration, and social interaction (Adjorlu et al. 2017; Mesa-Gresa et al. 2018; Adjorlu and Serafin 2020). Individuals with ASD face difficulties related to communication skills such as confusion, anxiety, phobias, and stress when are exposed to the public area. VR treatments aim to overcome the feelings of confusion and anxiety in unfamiliar or crowded environments (agoraphobia), such as public transportation, educational settings, supermarkets through stress management training (relaxation and breathing control) and 
sensory processing disorders (Adjorlu et al. 2017; Blume et al. 2017; Rossi et al. 2018). Malihi et al. (2020) argued that levels of anxiety and negative effects experienced by children with ASD while wearing HMDs or watching a monitor-displayed video were not significantly different. Contrariwise, children with ASD indicated that HMDs improve spatial presence and realism. Furthermore, children with ASD reported that HMDs were enjoyable, physically and visually comfortable, easy to use, and exciting (Newbutt et al. 2020). Even if children with ASD have a preference for more expensive and high-tech HMDs, Newbutt et al. (2020) suggested that low-tech options such as smartphone-based HMDs could be a suitable tool for relaxing, exploring an environment just before visiting the real world, and enhancing learning outcomes. In addition, according to Pallavicini and Pepe (2020), VR video games appear to be effective tools to elicit positive emotions and to decrease negative emotions and state anxiety in individuals. As studies on the effect of HMDs are at a very early stage and given the individual differences more research is needed.

Regarding addiction, most of the research was also directed to video games. According to the literature, many questions about the criteria that should be met for the diagnosis of "addiction" are raised. The debate over the distinction between high engagement and addiction has been going on for many years and according to data, it is still a matter of interest for researchers. Recently, the American Psychiatric Association (2013) included diagnostic criteria for Internet Gaming Disorder (IGD) [published in the appendix (Section III) of the Diagnostic and Statistical Manual for Mental Disorders (DSM-5)]. Nine symptoms were proposed, i.e. preoccupation, withdrawal symptoms, tolerance, unsuccessful attempts to control, loss of interest in previous hobbies/ entertainments, continued use despite known problems, deception of others, gaming to escape a negative mood, and jeopardizing friendships/education/jobs), of which at least five were needed for a diagnosis of IGD (Wichstrøm et al. 2019). "Gaming Disorder" (6C51) has recently been included in the beta version of the International Classification of Diseases (ICD-11) of WHO (2018), as well. Some studies concluded that IGD is associated with changes to the brain's reward system and mechanisms of loss of control and inhibition, and therefore IGD is classified as a behavioural addiction (Weinstein 2017; Weinstein and Lejoyeux 2020). Weinstein and Lejoyeux (2020) reviewed studies on the neurobiological correlation of addictive Internet use in adolescents and young adults. They concluded that brain research has shown that IGD shares typical neurobiological structural changes that are evident in other addictions. Advances in neuroscience identified addiction as a chronic brain disease with strong genetic, neurodevelopmental, and sociocultural components (Volkow and Morales 2015). Reward deficiency, reduced impulse control mechanisms, impaired decision making, and impulsivity occur in individuals diagnosed with IGD. Furthermore, brain structural changes, mainly reduction in grey-matter volume and white-matter density are also related to IGD. Comorbidity studies indicate that executive control networks in ADHD may increase the susceptibility to develop IGD. Adolescents with Internet addiction had higher ADHD symptoms, depression, social phobia, and hostility (Yen et al. 2007; Weinstein and Weizman 2012; Weinstein 2017; Weinstein and Lejoyeux 2020). However, Kuss et al. (2017) have criticized the DSM-5 and argued that Internet addiction and IGD are not the same and the differentiation between the two is conceptually significant. The neurophysiological underpinnings of VR addiction may differ from that of Internet use disorder (Madary and Metzinger 2016). In this context, the field of "problematic gaming behaviour" (Männikkö et al. 2015) is recognized by a lack of standardization, based on different aspects such as participants' characteristics, video game genre and diverse study goals (Palaus et al. 2017; Carbonell 2017).

Concerning high engagement and possibly excessive gaming, it may be nothing more than a "phase" of gamers, connecting the starting of the game to curiosity and the quitting to the decreased interest based on several factors (starting or quitting a game could relate either to personal reasons, e.g. friends quitted game, or to the game per se, e.g. disappointment by technical issues) (Alha et al. 2019). Furthermore, the physiological and measurable withdrawal symptoms should not be confused with negative emotions as a consequence of the sudden discontinuation of gameplay. The tolerance criterion (i.e. gamers' awareness that although they need to stop playing and desire to do so, they cannot stop) has high diagnostic accuracy. Another questionable criterion is "giving up other alternative activities". Giving up alternative activities is either a part of a developmental process (especially for children) or a symptom of depression which is often comorbid with addictive use of the Internet and gaming. The deception/covering up criterion has been also disputed among the scientific community. If children tend to hide and not tell the truth about games and time spent playing to their parents, it is suggesting that this criterion is an indication of further family relationships and family schedule management rather than a valid IGD criterion. Parent-child conflict, parental influence on gaming and familial dysfunctions may influence children's behaviour and lead them to media sources for support, comfort and relief, and therefore facilitate probable addiction (Schneider et al. 2017; Steve and Grubb 2018). Escaping from real-life problems may be indicative of negative emotional experiences and a primary problem of depression, anxiety, obesity, ADHDlike behaviours or other mental disorder, such as aggression, reduced empathy, lower life satisfaction (Weiss et al. 2011; Festl et al. 2013; Przybylski 2014; Kuss et al. 2017; Steve and Grubb 2018; Lavoie et al. 2020). 
The most popular worldwide type of online games is the Massively Multiplayer Online Role-Playing Games (MMORPGs). MMORPGs hold thousands of players simultaneously with no spatial or temporal limitation. At the same time encourage players to adopt different personas by their avatars, allowing social interactions and virtual community building, providing various motives to players and adapting to the individual needs. Thus, gamers play to achieve goals, to be social and to be immersed. For these reasons, MMORPGs have been shown to have a higher addictive potential than other game due to the motivations of achievement, socializing and escapism (Kuss et al. 2017). For a minority of gamers, these online worlds can substitute the social contexts of their real life. On the other hand, collective games such as MMORPGs may enhance face-to-face relationships which often extend friendships to real life, may increase the level of bonding and social interactions in the classroom may provide an additional communication frame and may reduce the potential symptoms of Internet addiction (Stavropoulos et al. 2017). However, the diagnosis of IGD remains unclear regarding whether or not gamers need to be engaged online, as IGD typically involves specific Internet games, but can also include offline games (Kuss et al. 2017). Nevertheless, the existing literature considering gaming addiction indicates that online games may increase the likelihood of addiction compared to offline games. So it seems very important to be proved whether the addiction is due to the Internet and online games or to the dynamics of gameplay and mechanisms that exist in offline games as well. Paulus et al. (2018) concluded that IGD development often reflects personal, familial, and environmental risk factors and comorbid conditions. However, according to Wichstrøm et al. (2019) symptoms of IGD are only marginally associated with symptoms of other psychiatric disorders and are predicted solely by social skills and emotion regulation deficits. Developing IGD requires several interacting internal factors (e.g. deficient self-regulatory and decision-making abilities as a consequence of dysexecutive problems, mood and reward system dysregulation, avoidant behaviour, low self-esteem, poor self-efficacy, and neurobiological factors such as altered grey matter volume, functional connectivity, and activation in specific brain regions), and external factors including familial, social, and game-related factor (Schneider et al. 2017; Paulus et al. 2018). Familial issues such as family violence and poor parental care pose as key risk factors of IGD. Communication and social interaction which reinforces meaningful feelings and self-regulation and reduces negative feelings such as isolation and boredom are important components of numerous games. Game structural elements, rewards, punishments, game narrative, immersion, screen time exposure, and inappropriate content, are some of the most influential game-related factors. Online and role-playing games are associated with a higher risk of addiction than offline games due to their inherent social reinforcements. Possible explanations between external factors and IGD are provided by behaviourism learning theory such as classical and operant conditioning, gratifications theory and social-cognitive theory (Paulus et al. 2018). As videogame addiction among adolescents was negatively associated with sleep duration, interventions aimed at problematic video gaming could improve adolescents' long-term cardio-metabolic health (Turel et al. 2016).

Lack of social interaction (Standen and Brown 2006) can also result from isolation due to a computer, specifically for a group facing a greater degree of social neglect. Isolation is related to beliefs that too much time with digital devices disconnects children from face-to-face social activities, family communication and physical activities (Resilient Educator 2020). Concerning hardware in educational settings, general and/or special education, it is challenging to examine whether desktop or specialized devices, such as smartphones, tablets, glasses, gloves, vests, gesture tracking, haptic devices, controllers stereoscopic, and HMDs are better suited for students (Kaimara et al. 2019b). One of the desktop advantages is the public nature of the screen that allows interactions between learners and tutor/educator or peers (Standen and Brown 2006). Furthermore, desktops are more affordable and even though lack full immersion capabilities, they are still popular and beyond their multitasking are cheaper than other types of VR systems (Carter 2012). Indeed, however, the conclusions of these researches are quite old and it should be noted that immersive technologies are constantly becoming more accessible, cheaper, available and easier to use and are supported by the so-called smartphone-based devices. Moreover, the increased ubiquitous ownership of PSDs has led researchers to investigate the impact of "bring your own device approach" (BYOD) to mobile enhanced learning (McLean 2016). Thus, the benefits of the desktop systems associated with creating a positive collaborative classroom climate and their affordability are re-examined. Collaborative learning is more encouraged while students use PSDs and share common experiences, especially with augmented reality applications, than if they are sitting in front of the desktop. Digital media increased opportunities for social contact and support (Reid Chassiakos et al. 2016). Children and adolescents who played games less than one hour a day presented higher levels of prosocial behaviour (i.e. actions beneficial to others e.g. helping, sharing, donating, collaborating, and volunteering), life satisfaction, and lower levels of negative effects such as hyperactivity, peer problems, emotional difficulties as well as sleep disorders (Granic et al. 2014; Przybylski 2014; Turel et al. 2016; Kardefelt-Winther 2017). Conversely, children 
who spent more than half of their daily free time on games appeared some negative behaviour. Lobel et al. (2017) studying the effect of video games on children's psychosocial well-being, concluded that only frequent competitive gaming (i.e. approximately $8 \mathrm{~h}$ or more per week) may be a risk factor for decreasing prosocial behaviour. Regarding the training of children and adolescents with ASD, VR has emerged as an effective tool for improving emotional and/or social skills, including emotion recognition, collaboration, and social interaction tasks (Newbutt et al. 2017; Mesa-Gresa et al. 2018).

\section{Summary and recommendations}

The impact of VRTs and gaming on children's overall development remain the focus of scientific debate. Approaching the issue is a difficult task and a complex long-term multifactorial process. A key research problem related to ethical issues and concerns arising from the use of cutting-edge technologies by children is related to the bioethics of human research. Aside from the general ethical issues of consent, awareness and information, adequate understanding and confidentiality, a major worry concerns potentially harmful consequences (Neill 2005). Therefore, experiments involving children are difficult to conduct and when are carried out last a few minutes. The majority of neuropsychological studies using VRTs have dealt with adults while empirical studies with children and adolescents are relatively rare (Nolin et al. 2016; Bailey and Bailenson 2017; Kenwright 2018). Thus, the results obtained are disputable. The impact of VRTs on children is not necessarily linear but can be explained by a curved relationship between well-being, content, individual differences, screen time, type of digital activity, and devices (Przybylski and Weinstein 2017). In this context, the authors examined the issue through a general mapping of trends across the three domains of children development: physical, cognitive and psychosocial.

In the domain of physical development, major topics of research comprise cybersickness, obesity, cardio-metabolic deficiencies, and sleep disorders. The general finding of these areas of physical development is interdependent and often the impact of VRTS and gaming in one area can affect the other. There is often a vicious cycle as, when children are engaged in an interesting game with great immersion, there is a risk of obesity, due to unhealthy eating habits and lack of physical activity. Obesity can lead to sleep disorders, but also sleep disorders due to blue light and low melatonin levels can lead to obesity with possible cardio-metabolic deficiencies factors (Calvert et al. 2013; Tosini et al. 2016; Turel et al. 2016, 2017; Fuller et al. 2017; Kenney and Gortmaker 2017; Cappuccio and Miller 2017; Gheller et al. 2019). Limiting screen time in children and adolescents from one to two hours before bedtime and, at the same time, using protective equipment, such as glasses that block blue light, can prevent sleep disorders and consequently their associated problems (Gottschalk 2019; Boyd 2020).

Cybersickness is another important aspect of research. Symptoms such as nausea and disorientation are very common but without having long-term effects (Tosini et al. 2016). As further research is required to assess the duration of cybersickness symptoms, it is suggested that the most effective method of recovering seems to be the limited use (about $15 \mathrm{~min}$ ) with satisfactory breaks between sessions (UK Department for Business Energy \& Industrial Strategy 2020).

Visual disturbance and fatigue caused by viewing VR content on HMD are due to vergence-accommodation conflict. Performing an oculomotor exercise, immediately before watching VR content on HMD have beneficial effects on ocular muscle and cranial nerve function and also is considered a successful way to relieve cybersickness (Park et al. 2017). Gotsis (as cited in Gent, 2016) argued that while children may not understand how to communicate their eye-related problems and may not have the reflexes to remove HMDs if they find them uncomfortable, it does not necessarily mean that VR is not safe for children. Conversely, children's inability to focus within HMDs may have diagnostic value. Similarly, screen time exposure is linked to increased risks and concerns (Gent 2016; Boyd 2020; Wong et al. 2020; Tychsen and Foeller 2020). In 2018, the American Academy of Ophthalmology (2018) concluded that the increasing prevalence of myopia worldwide is associated with almost all activities performed close to eyes, not only screen-related works but also reading traditional books. American Academy of Ophthalmology (2020) suggests the 20-20-20 rule for preventing and relieving digital eyestrain, that is 20 -s break every 20 min by looking 20 feet away, during extended reading, writing or other intensive near work that may also cause eyestrain (Boyd 2020).

Although investigation regarding cybersickness and eyestrain so far seems to be comforting (Park et al. 2017; Wong et al. 2020; Tychsen and Foeller 2020), there are general concerns due to the limited up to date research for longterm results (Gent 2016). For these reasons, many immersive media hardware companies have specified that their products are not permitted for children under age 12 (Sony Interactive Entertainment 2020) or 13 (Oculus 2018; Samsung 2020) and older children should not use their products without adult supervision (HTC 2019; Sobel 2019).

The second aspect of indivisible child development refers to cognition. Areas studied are attention, learning in general, spatial cognition and general cognition. Although the results for the use of VRTS and games in education are very promising (Gee 2008; de Freitas and Liarokapis 2011; Girard et al. 2013; Granic et al. 2014; Boyle et al. 2016; de Freitas 
2018; Erhel and Jamet 2019; Fokides and Chachlaki 2020), there are no positive outcomes to respect to specific components of cognition (Mayer 2019; Kaimara et al. 2019a; Parong and Mayer 2020). This conclusion is probably due to the lack of focused applications on a single cognitive skill. However, the results of research to improve attention are particularly encouraging. Studies have focused on children with ADHD, as they are a population characterized by disorganization, and/or hyperactivity-impulsivity directly associated with limited attention and distraction. There is clear evidence that VRTs and video games can assist children to focus on the purpose of the designed intervention (Cho et al. 2004; Blume et al. 2017; Kim et al. 2020).

Another major concern is related to the confusion that children may have with mixing the virtual with the real world and the potential dangers posed by this confusion. The confusion caused by VEs, as well as any children's activity incorporates imaginary worlds that often lead them to identify with the avatars or heroes (cf., fairy tales, legends, customs, etc.) confirms that different forms of media may manipulate the human experience and adults' role is crucial to help children understand the difference between fantasy and reality (Standen and Brown 2006; Segovia and Bailenson 2009; Bailey and Bailenson 2017; Sobel 2019). Though the American Academy of Pediatrics recognizes the potential benefit of mobile/interactive technologies for children especially through well-designed educational materials, it continues to express concerns about their overuse during this crucial period of rapid brain development (American Academy of Pediatrics 2016b, p. 1).

The third direction of the current review focuses on the effects of VRTs and games on psychosocial development. Most frequently reported mental health challenges and concerns extend to areas such as anxiety, addiction, and social isolation. Much of the study regarding anxiety involved children with ASD. Anxiety is a common feature of children with ASD. While one would expect children with ASD to experience high levels of stress especially during the use of HMDs and due to sensory processing disorders, nevertheless the children reported high spatial presence and engagement. The devices were also described as enjoyable, natural and visually comfortable, easy to use and exciting (Adjorlu et al. 2017; Newbutt et al. 2020). On the other hand, HMDs may not be tolerated by all individual with ASD, so general safety concerns continue, supervised use is required and limited access to such devices until larger studies demonstrate their safety (Dixon et al. 2019).

In terms of addiction, the field is blurred. Although criteria for gaming addiction have recently been identified by the American Psychiatric Association (2013) and WHO (2018), the problematic gaming behaviour has not been clarified whether it is due to gambling, the Internet or gaming technology (Männikkö et al. 2015; Weinstein 2017;
Kuss et al. 2017). Additionally, there is a lack of standardization for participants' characteristics, video game genre and diverse study goals (Palaus et al. 2017). Though researchers approaching the issue of gaming addiction concluded that many children resort to gaming for consolation, as no one in the family deals with them (Young 2009; Schneider et al. 2017; Steve and Grubb 2018), from a wide range of possible predictive causal factors examined, only low social competence and poor emotion regulation skills predict IGD-symptoms (Wichstrøm et al. 2019). However, family dysfunction related to parents' socioeconomic status and mental health, conflicting and abusive parent-child relationships, parental influence on gaming, household composition, and escape from family problems could make it easier for addiction and IGD to develop (Schneider et al. 2017). According to Festl et al (2013), to answer the question of whether extensive gaming leads to problematic behaviour or whether individuals with an impulse control disorder tend to engage in many forms of excessive behaviour, including intensive gaming more longitudinal data are needed.

On the other hand, games can facilitate children collaboration and prosocial behaviours, especially in times of social distancing. Currently, due to the COVID-19 pandemic, most countries have chosen social distancing as a solution to suppress the viral spread, which has led to social isolation. World Health Organization (2020) has supported the gaming industry's online social media campaign (\#PlayApartTogether) for socializing, relaxation and stress reduction. MMORPGs can improve social interaction and thus eliminate social isolation (World Health Organization 2020). In VR communities, decisions need to be made quickly about whom to trust, whom to reject, and how to most effectively lead a group. Granic et al (2014) argued that gamers are rapidly acquiring social skills and prosocial behaviour that might generalize to their peer and family relations outside the gaming environment. The increased online gaming has been perceived as complementary to public health efforts to promote social distancing during the \#StayAtHome period, to support physical and psychological well-being and to encourage social interaction and collaboration, as gaming is not necessarily problematic and reduces loneliness. However, it is suggested that video games must incorporate messages about SARS-CoV-2 prevention guidelines combined with mental health information (\#HealthyAtHome). A balanced screen time exposure and gaming are strongly recommended to prevent addiction and IGD when the COVID-19 crisis has passed (King et al. 2020).

For ethical issues, it is strongly suggested a healthy Family Media Use Plan that is individualized for a specific child, teenager and family, accordingly to each child's age, health, temperament and developmental stage and focused on appropriate balance between screen time/online time and other (Reid Chassiakos et al. 2016; American Academy of 
Pediatrics 2019). Overall, the most harmful to children's health and well-being, on the evidence to date, is not related to VRTs and games but to screen exposure time. Hence, the exposure of children and adolescents to screens should be subject to parental control (Viner et al. 2019).

The Organisation for Economic Co-operation and Development (OECD) (Gottschalk 2019, p.13) stated that "shock headlines touting total restructuring of children's mind as a result of technology use are not based on empirical evidence and are inaccurate". Indeed, the majority of concerns about video games being played by children have been voiced by professionals in news agencies and parent magazines (Tychsen and Foeller 2020). Indicative headlines such as "Video games are as addictive as crack cocaine or gambling to some players, warns WHO", confuse, mislead and even terrorise parents and teachers. The popular scientific claim that time spent on digital technology could make children addicted is a misrepresentation of existing knowledge (Kardefelt-Winther 2017). It is a moral imperative for those who shape and influence public opinion, instead of pompous statements that target, accuse and stigmatize games, and link them to drug use, to ensure more research based on scientific evidence.

\section{Implications, limitations and future research}

The literature review so far has found that both systematic reviews and empirical researches usually focused on a single domain of development, whether physical, cognitive or psychosocial. The objectives of this paper were to provide an overview of the impact of VRTs and games on children's overall development. Thus, the categorization of impacts into physical, cognitive and psychosocial domains is one of the paper's contributions. However, there are limitations to this work that have to be acknowledged. The above limitations can function as guidelines for future research. The first limitation relates to the ethics of research on children. Thus, a few studies provide empirical data with children and usually with a small number of subjects of different ages. These results elicit generalization problems. Another limitation of the research, even by observations and records, is related to the lack of long-term and longitudinal conclusions from exposure to this contemporary technology, as it is very recent. A third limitation of this review is that it did not extend to video game content. The study encompasses technical issues of both the technology (cf., immersion, imagination, involvement, etc.) and games structural features (cf., rules, competition, gameplay, etc.). For these reasons, future research will include content issues such as violence, bullying, cyberbullying, and antisocial behaviour and their impact on children emotional development. For these reasons, future research will include content issues such as violence, bullying, cyberbullying and antisocial behaviour and their impact on children's emotional development. It is also important to conduct a new systematic literature review on the effects of long-term exposure to screens, compulsory distance education and the amount of time spent playing games due to the prolonged quarantine caused by the COVID-19 pandemic.

\section{Conclusion}

The purpose of the current review was to provide the background and state-of-the-art research regarding children safety during and after VRTs use and to highlight the significance and necessity of ongoing surveys in this field as technology evolves. VRTs influence children's physical, cognitive and psychosocial development at different ages and stages. The effects could be either positive or negative. Of the 85 studies analysed, 28 relate to the physical domain, 38 to cognitive development and 29 to psychosocial development, while 5 of them refer to two developmental domains and 1 to all three domains. The majority of researchers agree that prominent concerns arise from the overuse of screens and HMDs. More specifically, regarding the physical domain, worries refer to cybersickness, the prevalence of visual symptoms, obesity and sleep disorders. Blue light induces photoreceptor damage and affects the circadian system. The chronic disruption of one of the most basic circadian rhythms leads to a vicious circle between sleep disorders and unhealthy behaviours. Poor nutritional habits in combination with reduced physical activity cause obesity and long-term cardio-metabolic deficiencies. Concerning cognitive development, only positive or neutral effects were observed. The contribution of VR applications to the education and support of children with ASD and/or ADHD is significant. Regardless of the effectiveness of current VR applications, this technology seems to be very promising with academics and professionals developing more and more targeted tasks. The greatest concern was identified in the psychosocial domain. The combination of the unique components of VRTs and games structural elements has a key role to play. Children are increasingly involved in virtual worlds, with both the World Health Organization and the International Classification of Diseases provide risk warnings about possible gaming-related addictions and problem behaviours. However, it has not yet been clarified whether these behaviours are caused by the Internet, VRTs or gaming technology. Nevertheless, even researches that conclude the adverse effects of VRTs and games on children connect these findings to unrestricted and unsupervised use. Thorough long-term research is needed for safe conclusions, as new technology, in terms of software 
and hardware, is constantly emerging. Ethical issues which arise can be resolved when potential users, parents, children, and teachers understand exactly what VRTs are and what they can achieve. Therefore, academic communities ought to investigate and offer evidence-based responses to parents, teachers and healthcare personnel concerns about the proper or harmful use of technology by children.

\section{Declarations}

Conflict of interest The authors declare that they have no conflict of interest.

\section{References}

Abt CC (1975) Serious games. Viking Compass, New York

Adjorlu A, Hoeg ER, Mangano L, Serafin S (2017) Daily living skills training in virtual reality to help children with autism spectrum disorder in a real shopping scenario. In: 2017 IEEE International Symposium on Mixed and Augmented Reality (ISMARAdjunct). IEEE, Nantes, pp 294-302

Adjorlu A, Serafin S (2019) Head-Mounted Display-Based Virtual Reality as a Tool to Teach Money Skills to Adolescents Diagnosed with Autism Spectrum Disorder. In: Brooks A, Brooks E, Sylla C (eds) Interactivity, game creation, design, learning, and innovation. ArtsIT 2018, DLI 2018. Lecture notes of the institute for computer sciences, social informatics and telecommunications engineering, vol 265. Springer, Cham. https://doi.org/10. 1007/978-3-030-06134-0_48

Adjorlu A, Serafin S (2020) Head-mounted display-based virtual reality as a tool to reduce disruptive behavior in a student diagnosed with autism spectrum disorder. In: Brooks A, Brooks EI (eds) Interactivity, game creation, design, learning, and innovation: 8th EAI international conference, ArtsIT 2019, and 4th EAI international conference, DLI 2019, proceedings. Springer, Cham, pp 739-748

Alha K, Koskinen E, Paavilainen J, Hamari J (2019) Why do people play location-based augmented reality games: a study on Pokémon GO. Comput Human Behav 93:114-122. https://doi.org/10. 1016/j.chb.2018.12.008

American Academy of Ophthalmology (2018) Is too much screen time harming children's vision? The American Academy of Ophthalmology helps parents separate the facts from fiction. https:// www.aao.org/newsroom/news-releases/detail/is-too-muchscreen-time-harming-childrens-vision

American Academy of Ophthalmology (2020) Ophthalmologists anticipate a school year marked by complaints of eye strain. https:// www.aao.org/newsroom/news-releases/detail/ophthalmologistsanticipate-eye-strain-complaints

American Academy of Pediatrics (2016a) Cell phone radiation \& children's health: what parents need to know. https://www.healt hychildren.org/English/safety-prevention/all-around/Pages/CellPhone-Radiation-Childrens-Health.aspx

American Academy of Pediatrics (2016b) Media and young minds. Pediatrics 138:e20162591. https://doi.org/10.1542/peds. 2016-2591

American Academy of Pediatrics (2019) Family media plan. https:// www.healthychildren.org/English/media/Pages/default.aspx
American Psychiatric Association (2013) Diagnostic and Statistical Manual of Mental Disorders (DSM-5) - Fifth Edition. American Psychiatric Association, Arlington, VA

Aromataris E, Fernandez R, Godfrey CM, Holly C, Khalil H, Tungpunkom P (2015) Summarizing systematic reviews. Int J Evid Based Healthc 13:132-140. https://doi.org/10.1097/XEB.00000 00000000055

Ayres AJ, Tickle LS (1980) Hyper-responsivity to touch and vestibular stimuli as a predictor of positive response to sensory integration procedures by autistic children. Am J Occup Ther 34:375-381. https://doi.org/10.5014/ajot.34.6.375

Bailey JO, Bailenson JN (2017) Immersive virtual reality and the developing child. In: Blumberg FC, Brooks PJ (eds) Cognitive Development in Digital Contexts. Elsevier, pp 181-200

Behr K-M, Nosper A, Klimmt C, Hartmann T (2005) Some practical considerations of ethical issues in VR research. Presence: Teleoperators Virtual Environ 14:668-676. https://doi.org/10.1162/ 105474605775196535

Bello Aliyu M (2017) Efficiency of boolean search strings for information retrieval. Am J Eng Res 6:216-222

Bennett CR, Bailin ES, Gottlieb TK, Bauer CM, Bex PJ, Merabet LB (2018) Assessing visual search performance in ocular compared to cerebral visual impairment using a virtual reality simulation of human dynamic movement. In: Proceedings of the Technology, Mind, and Society (TechMindSociety '18). ACM Press, New York, pp 1-6

Blume F, Hudak J, Dresler T, Ehlis A-C, Kühnhausen J, Renner TJ, Gawrilow C (2017) NIRS-based neurofeedback training in a virtual reality classroom for children with attention-deficit/hyperactivity disorder: study protocol for a randomized controlled trial. Trials 18:41. https://doi.org/10.1186/s13063-016-1769-3

Boyd K (2020) Computers, digital devices, and eye strain. https://www. aao.org/eye-health/tips-prevention/computer-usage

Boyle EA, Hainey T, Connolly TM, Gray G, Earp J, Ott M, Lim T, Ninaus M, Ribeiro C, Pereira J (2016) An update to the systematic literature review of empirical evidence of the impacts and outcomes of computer games and serious games. Comput Educ 94:178-192. https://doi.org/10.1016/j.compedu.2015.11.003

Brereton P, Kitchenham BA, Budgen D, Turner M, Khalil M (2007) Lessons from applying the systematic literature review process within the software engineering domain. J Syst Softw 80:571583. https://doi.org/10.1016/j.jss.2006.07.009

Bruck S, Watters P (2009) Cybersickness and Anxiety During Simulated Motion: Implications for VRET. Stud Health Technol Inform 144:169-173. https://doi.org/10.3233/ 978-1-60750-017-9-169

Burdea GC, Coiffet P (2003) Virtual reality technology, 2nd edition. Wiley, New Jersey

Calvert SL, Staiano AE, Bond BJ (2013) Electronic gaming and the obesity crisis. New Dir Child Adolesc Dev 2013:51-57. https:// doi.org/10.1002/cad.20031

Cappuccio FP, Miller MA (2017) Sleep and cardio-metabolic disease. Curr Cardiol Rep 19:110. https://doi.org/10.1007/ s11886-017-0916-0

Carbonell X (2017) From Pong to Pokemon Go, catching the essence of the internet gaming disorder diagnosis. J Behav Addict 6:124127. https://doi.org/10.1556/2006.6.2017.010

Carter B (2012) Virtual harlem: an innovative past, an evolving present and an exciting future. In: Gardner M, Garnier F, Delgado Kloos C (eds) Proceedings of the 2nd European immersive initiative summit. Universidad Carlos III de Madrid, Paris, France, pp 24-37

Chang S, Hsu T, Kuo W, Jong MS (2020) Effects of applying a VRbased two-tier test strategy to promote elementary students' learning performance in a geology class. Br J Educ Technol 51:148-165. https://doi.org/10.1111/bjet.12790 
Charrois TL (2015) Systematic reviews: what do you need to know to get started? Can J Hosp Pharm. https://doi.org/10.4212/cjhp. v68i2.1440

Checa D, Bustillo A (2020) A review of immersive virtual reality serious games to enhance learning and training. Multimed Tools Appl 79:5501-5527. https://doi.org/10.1007/ s11042-019-08348-9

Cho B-H, Kim S, Shin DI, Lee JH, Min Lee S, Young Kim I, Kim SI (2004) Neurofeedback training with virtual reality for inattention and impulsiveness. CyberPsychology Behav 7:519-526. https:// doi.org/10.1089/cpb.2004.7.519

Clark RE, Yates K, Early S, Moulton K (2010) An analysis of the failure of electronic media and discovery-based learning. In: Silber KH, Foshay WR, Watkins R, Leigh D, Moseley JL, Dessinger JC (eds) Handbook of improving performance in the workplace: volumes 1-3. Wiley, Hoboken, pp 263-297

Connors EC, Chrastil ER, Sánchez J, Merabet LB (2014) Action video game play and transfer of navigation and spatial cognition skills in adolescents who are blind. Front Hum Neurosci 8:133. https:// doi.org/10.3389/fnhum.2014.00133

Dalgarno B, Lee MJW (2010) What are the learning affordances of 3-D virtual environments? Br J Educ Technol 41:10-32. https://doi. org/10.1111/j.1467-8535.2009.01038.x

Davies PL, Gavin WJ (2007) Validating the diagnosis of sensory processing disorders using EEG technology. Am J Occup Ther 61:176-189. https://doi.org/10.5014/ajot.61.2.176

de Freitas S (2018) Are games effective learning tools? A review of educational games. Educ Technol Soc 21:74-84

de Freitas S, Liarokapis F (2011) Serious games: a new paradigm for education? In: Ma M, Oikonomou A, Jain L (eds) Serious games and edutainment applications. Springer, London, pp 9-23

Dixon DR, Miyake CJ, Nohelty K, Novack MN, Granpeesheh D (2019) Evaluation of an immersive virtual reality safety training used to teach pedestrian skills to children with autism spectrum disorder. Behav Anal Pract. https://doi.org/10.1007/s40617-019-00401-1

Dużmańska N, Strojny P, Strojny A (2018) Can simulator sickness be avoided? A review on temporal aspects of simulator sickness. Front Psychol. https://doi.org/10.3389/fpsyg.2018.02132

Erhel S, Jamet E (2019) Improving instructions in educational computer games: exploring the relations between goal specificity, flow experience and learning outcomes. Comput Human Behav 91:106-114. https://doi.org/10.1016/j.chb.2018.09.020

Fernández C, de Salles AA, Sears ME, Morris RD, Davis DL (2018) Absorption of wireless radiation in the child versus adult brain and eye from cell phone conversation or virtual reality. Environ Res 167:694-699. https://doi.org/10.1016/j.envres.2018.05.013

Festl R, Scharkow M, Quandt T (2013) Problematic computer game use among adolescents, younger and older adults. Addiction 108:592-599. https://doi.org/10.1111/add.12016

Fokides E, Chachlaki F (2020) 3D Multiuser virtual environments and environmental education: the virtual island of the mediterranean monk seal. Technol Knowl Learn 25:1-24. https://doi.org/10. 1007/s10758-019-09409-6

Fokides E (2020) Digital educational games in primary education. In: Daniela L (ed) Epistemological approaches to digital learning in educational contexts. Routledge, pp 54-68

Fowler C (2015) Virtual reality and learning: where is the pedagogy? Br J Educ Technol. https://doi.org/10.1111/bjet.12135

Freina L, Ott M (2015) A literature review on immersive virtual reality in education: state of the art and perspectives. In: Proceedings of the International Scientific Conference eLearning and Software for Education (eLSE), April 23-24, 2015. 'Carol I' National Defence University, Bucharest, Romania, pp 133-141
Fuller C, Lehman E, Hicks S, Novick MB (2017) Bedtime use of technology and associated sleep problems in children. Glob Pediatr Heal. https://doi.org/10.1177/2333794X17736972

Gee JP (2008) Learning and games. In: Salen K (ed) The ecology of games: Connecting youth, games, and learning, pp 21-40. Cambridge, MA: The MIT Press. https://doi.org/10.1162/dmal. 9780262693646.021

Gent E (2016) Are virtual reality headsets safe for children? A lack of data and guidelines is leaving consumers in the dark about virtual reality's potential negative side effects for kids. Sci Am. https:// www.scientificamerican.com/article/are-virtual-reality-heads ets-safe-for-children/

Gheller BJF, Totosy de Zepetnek JO, Welch JM, Rossiter MD, Luhovyy B, Brett NR, Bellissimo N (2019) Effect of video game playing and a glucose preload on subjective appetite, subjective emotions, and food intake in overweight and obese boys. Appl Physiol Nutr Metab 44:248-254. https://doi.org/10.1139/ apnm-2018-0281

Girard C, Ecalle J, Magnan A (2013) Serious games as new educational tools: How effective are they? A meta-analysis of recent studies. J Comput Assist Learn 29:207-219. https://doi.org/10.1111/j. 1365-2729.2012.00489.x

González CS, Gómez N, Navarro V, Cairós M, Quirce C, Toledo P, Marrero-Gordillo N (2016) Learning healthy lifestyles through active videogames, motor games and the gamification of educational activities. Comput Human Behav 55:529-551. https://doi. org/10.1016/j.chb.2015.08.052

Gottschalk F (2019) Impacts of technology use on children: exploring literature on the brain, cognition and well-being. OECD Educ Work Pap 195:45. https://doi.org/10.1787/8296464e-en

Granic I, Lobel A, Engels RCME (2014) The benefits of playing video games. Am Psychol 69:66-78. https://doi.org/10.1037/a0034857

Greuter S, Woodcock R, Torre L, Douglass A, Sampson G, Chong L, Armitage J, Backhouse S (2020) AmblyopiaVR: immersive game-based virtual reality system for the treatment of amblyopia. In: Proceedings of Australasian computer science week (ACSW 2020). ACM, New York, pp 1-5

Gunter GA, Kenny RF, Vick EH (2006) A case for a formal design paradigm for serious games. J Int Digit Media Arts Assoc 3:93-105

Heilig LM (1960) Stereoscopic-television apparatus for individual use. https://patentimages.storage.googleapis.com/81/df/f1/f6cc2106f8 c7ab/US2955156.pdf

Heilig LM (1962) Sensorama stimulator. https://patentimages.stora ge.googleapis.com/90/34/2f/24615bb97ad68e/US3050870.pdf

Heim M (1998) Virtual realism. Oxford University Press, New York

Hirota M, Kanda H, Endo T, Miyoshi T, Miyagawa S, Hirohara Y, Yamaguchi T, Saika M, Morimoto T, Fujikado T (2019) Comparison of visual fatigue caused by head-mounted display for virtual reality and two-dimensional display using objective and subjective evaluation. Ergonomics 62:759-766. https://doi.org/ 10.1080/00140139.2019.1582805

HTC (2019) Health and safety guide. Vive legal documents. https:// www.htc.com/us/terms/vive/

Ijsselsteijn WA (2005) History of telepresence. In: Sikora O, Peter S, Thomas K (eds) 3D videocommunication: algorithms, concepts and real-time systems in human centred communication. Wiley, Chichester, pp 5-21

Jeong S, Shin WS, Park I (2015) Students' use of notebook computers in the college classroom: benefits and pitfalls. Educ Technol Int $16: 31-57$

Kade D (2015) Ethics of virtual reality applications in computer game production. Philosophies 1:73-86. https://doi.org/10.3390/philo sophies 1010073

Kaimara P, Deliyannis I (2019) Why should i play this game? The role of motivation in smart pedagogy. In: Daniela L (ed) Didactics 
of smart pedagogy. Springer International Publishing, Cham, pp 113-137

Kaimara P, Fokides E, Oikonomou A, Atsikpasi P, Deliyannis I (2019a) Evaluating 2D and 3D serious games: the significance of studentplayer characteristics. Dialogoi! Theory Prax Educ 5:36-56. https://doi.org/10.12681/dial.20704

Kaimara P, Poulimenou S-M, Oikonomou A, Deliyannis I, Plerou A (2019b) Smartphones at schools? Yes, why not? Eur J Eng Res Sci. https://doi.org/10.24018/ejers.2019.0.CIE.1288

Kaimara P, Fokides E, Plerou A, Atsikpasi P, Deliyannis I (2020a) Serious games effect analysis on player's characteristics. Int J Smart Educ Urban Soc 11:75-91. https://doi.org/10.4018/IJSEUS. 2020010106

Kaimara P, Plerou A, Deliyannis I (2020b) Cognitive enhancement and brain-computer interfaces: potential boundaries and risks. In: Vlamos P (ed) GeNeDis 2018. Advances in experimental medicine and biology. Springer, Cham, pp 275-283

Kardefelt-Winther D (2017) How does the time children spend using digital technology impact their mental well-being, social relationships and physical activity? An evidence-confused literature review. Innocenti Discussion Paper 2017-02, UNICEF Office of Research - Innocenti, Florence

Kelly KR, Jost RM, Dao L, Beauchamp CL, Leffler JN, Birch EE (2016) Binocular iPad game vs patching for treatment of amblyopia in children. JAMA Ophthalmol 134:1402. https://doi.org/10. 1001/jamaophthalmol.2016.4224

Kenney EL, Gortmaker SL (2017) United States adolescents' television, computer, videogame, smartphone, and tablet use: associations with sugary drinks, sleep, physical activity, and obesity. J Pediatr 182:144-149. https://doi.org/10.1016/j.jpeds. 2016.11.015

Kenny R, Gunter G (2011) Factors affecting adoption of video games in the classroom. J Interact Learn Res 22:259-276

Kenwright B (2018) Virtual reality: ethical challenges and dangers [opinion]. IEEE Technol Soc Mag 37:20-25. https://doi.org/ 10.1109/MTS.2018.2876104

Kim S, Ryu J, Choi Y, Kang Y, Li H, Kim K (2020) Eye-contact game using mixed reality for the treatment of children with attention deficit hyperactivity disorder. IEEE Access 8:4599646006. https://doi.org/10.1109/ACCESS.2020.2977688

King DL, Delfabbro PH, Billieux J, Potenza MN (2020) Problematic online gaming and the COVID-19 pandemic. J Behav Addict 9:184-186. https://doi.org/10.1556/2006.2020.00016

Koops MC, Verheul I, Tiesma R, de Boer C-W, Koeweiden RT (2016) Learning differences between $3 \mathrm{D}$ vs. $2 \mathrm{D}$ entertainment and educational games. Simul Gaming 47:159-178. https://doi. org/10.1177/1046878116632871

Koutsos TM, Menexes GC, Dordas CA (2019) An efficient framework for conducting systematic literature reviews in agricultural sciences. Sci Total Environ 682:106-117. https://doi.org/ 10.1016/j.scitotenv.2019.04.354

Kramida G (2016) Resolving the vergence-accommodation conflict in head-mounted displays. IEEE Trans vis Comput Graph 22:1912-1931. https://doi.org/10.1109/TVCG.2015.2473855

Kuss DJ, Griffiths MD, Pontes HM (2017) Chaos and confusion in DSM-5 diagnosis of internet gaming disorder: issues, concerns, and recommendations for clarity in the field. J Behav Addict 6:103-109. https://doi.org/10.1556/2006.5.2016.062

Lamb RL, Annetta L, Firestone J, Etopio E (2018) A meta-analysis with examination of moderators of student cognition, affect, and learning outcomes while using serious educational games, serious games, and simulations. Comput Human Behav 80:158-167. https://doi.org/10.1016/j.chb.2017.10.040

Lanier J, Biocca F (1992) An insider's view of the future of virtual reality. J Commun 42:150-172. https://doi.org/10.1111/j.14602466.1992.tb00816.x
LaViola JJ (2000) A discussion of cybersickness in virtual environments. ACM SIGCHI Bull 32:47-56. https://doi.org/10.1145/ 333329.333344

Lavoie R, Main K, King C, King D (2020) Virtual experience, real consequences: the potential negative emotional consequences of virtual reality gameplay. Virtual Real. https://doi.org/10. 1007/s10055-020-00440-y

Lee KM (2004) Presence, explicated. Commun Theory 14:27-50. https://doi.org/10.1111/j.1468-2885.2004.tb00302.x

Lobel A, Engels RCME, Stone LL, Burk WJ, Granic I (2017) Video gaming and children's psychosocial wellbeing: a longitudinal study. J Youth Adolesc 46:884-897. https://doi.org/10.1007/ s10964-017-0646-Z

Lombard M, Ditton T (1997) At the heart of it all: the concept of presence. J Comput Commun. https://doi.org/10.1111/j.10836101.1997.tb00072.x

Madary M, Metzinger TK (2016) Recommendations for good scientific practice and the consumers of VR-Technology. Front Robot AI 3:1-23. https://doi.org/10.3389/frobt.2016.00003

Makransky G, Borre-Gude S, Mayer RE (2019) Motivational and cognitive benefits of training in immersive virtual reality based on multiple assessments. J Comput Assist Learn 35:691-707. https://doi.org/10.1111/jcal.12375

Malihi M, Nguyen J, Cardy RE, Eldon S, Petta C, Kushki A (2020) Short report: evaluating the safety and usability of headmounted virtual reality compared to monitor-displayed video for children with autism spectrum disorder. Autism 24:19241929. https://doi.org/10.1177/1362361320934214

Männikkö N, Billieux J, Kääriäinen M (2015) Problematic digital gaming behavior and its relation to the psychological, social and physical health of Finnish adolescents and young adults. J Behav Addict. https://doi.org/10.1556/2006.4.2015.040

Marker C, Gnambs T, Appel M (2019) Exploring the myth of the chubby gamer: a meta-analysis on sedentary video gaming and body mass. Soc Sci Med. https://doi.org/10.1016/j.socscimed. 2019.05.030

Mayer R (2019) Computer games in education. Annu Rev Psychol 70:531-549. https://doi.org/10.1146/annur ev-psych-010418-102744

McLean KJ (2016) The implementation of bring your own device (BYOD) in primary [elementary] schools. Front Psychol. https:// doi.org/10.3389/fpsyg.2016.01739

Mesa-Gresa P, Gil-Gómez H, Lozano-Quilis J-A, Gil-Gómez J-A (2018) Effectiveness of virtual reality for children and adolescents with autism spectrum disorder: an evidence-based systematic review. Sensors 18:2486. https://doi.org/10.3390/s18082486

Moher D, Liberati A, Tetzlaff J, Altman DG (2010) Preferred reporting items for systematic reviews and meta-analyses: the PRISMA statement. Int J Surg. https://doi.org/10.1016/j.ijsu.2010.02.007

Molina-Carmona R, Pertegal-Felices M, Jimeno-Morenilla A, MoraMora H (2018) Virtual reality learning activities for multimedia students to enhance spatial ability. Sustainability 10:1074. https://doi.org/10.3390/su10041074

Moreau D, Mansy-Dannay A, Clerc J, Guerrien A (2010) Academic program and mental rotation performance: evidence for a developmental effect on individual differences in early adulthood. Educ Sci Psychol 17:21-28

National Academies of Sciences Engineering and Medicine (2018) How people learn II. National Academies Press, Washington

Neill SJ (2005) Research with children: a critical review of the guidelines. J Child Heal Care 9:46-58. https://doi.org/10.1177/13674 93505049646

Newbutt N, Sung C, Kuo J, Leahy MJ (2017) The acceptance, challenges, and future applications of wearable technology and virtual reality to support people with autism spectrum disorders. In: Brooks A, Brahnam S, Kapralos B, Jain L (eds) Recent advances 
in technologies for inclusive well-being, intelligent systems reference library, vol 119. Springer, Cham, pp 221-241

Newbutt N, Bradley R, Conley I (2020) Using virtual reality headmounted displays in schools with autistic children: views, experiences, and future directions. Cyberpsychol Behav Soc Netw 23:23-33. https://doi.org/10.1089/cyber.2019.0206

Nolin P, Stipanicic A, Henry M, Lachapelle Y, Lussier-Desrochers D, Rizzo AS, Allain P (2016) ClinicaVR: classroom-CPT: a virtual reality tool for assessing attention and inhibition in children and adolescents. Comput Human Behav 59:327-333. https://doi.org/ 10.1016/j.chb.2016.02.023

Oculus (2018) Oculus terms of service. https://www.oculus.com/legal/ terms-of-service/

Oliveira CB, Pinto RZ, Saraiva BTC, Tebar WR, Delfino LD, Franco MR, Silva CCM, Christofaro DGD (2020) Effects of active video games on children and adolescents: a systematic review with meta-analysis. Scand J Med Sci Sports 30:4-12. https://doi.org/ $10.1111 / \mathrm{sms} .13539$

Paez A (2017) Grey literature: an important resource in systematic reviews. J Evid Based Med 10:233-240. https://doi.org/10.1111/ jebm. 12265

Palaus M, Marron EM, Viejo-Sobera R, Redolar-Ripoll D (2017) Neural basis of video gaming: a systematic review. Front Hum Neurosci. https://doi.org/10.3389/fnhum.2017.00248

Pallavicini F, Pepe A (2020) Virtual reality games and the role of body involvement in enhancing positive emotions and decreasing anxiety: within-subjects pilot study. JMIR Ser Games 8:e15635. https://doi.org/10.2196/15635

Park WD, Jang SW, Kim YH, Kim GA, Son W, Kim YS (2017) A study on cyber sickness reduction by oculo-motor exercise performed immediately prior to viewing virtual reality (VR) content on head mounted display (HMD). Vibroeng Proc 14:260-264. https://doi. org/10.21595/vp.2017.19170

Parong J, Mayer RE (2020) Cognitive consequences of playing braintraining games in immersive virtual reality. Appl Cogn Psychol 34:29-38. https://doi.org/10.1002/acp.3582

Parsons TD (2019) Neuroethics in educational technology: keeping the brain in mind when developing frameworks for ethical decisionmaking. In: Parsons T, Lin L, Cockerham D (eds) Mind, brain and technology. Educational communications and technology: issues and innovations. Springer Cham, pp 195-209

Passig D, Tzuriel D, Eshel-Kedmi G (2016) Improving children's cognitive modifiability by dynamic assessment in 3D immersive virtual reality environments. Comput Educ 95:296-308. https://doi. org/10.1016/j.compedu.2016.01.009

Paulus FW, Ohmann S, von Gontard A, Popow C (2018) Internet gaming disorder in children and adolescents: a systematic review. Dev Med Child Neurol 60:645-659. https://doi.org/10.1111/ dmcn.13754

Peters M, Lehmann W, Takahira S, Takeuchi Y, Jordan K (2006) Mental rotation test performance in four cross-cultural samples $(\mathrm{N}=$ 3367): overall sex differences and the role of academic program in performance. Cortex 42:1005-1014. https://doi.org/10.1016/ S0010-9452(08)70206-5

Prensky M (2007) Fun, play and games: What makes games engaging. In: Digital game-based learning. Paragon House, St Paul, Minnesota, pp 105-144

Przybylski AK (2014) Electronic gaming and psychosocial adjustment. Pediatrics 134:e716-e722. https://doi.org/10.1542/peds. 2013-4021

Przybylski AK, Weinstein N (2017) A large-scale test of the goldilocks hypothesis: quantifying the relations between digital-screen use and the mental well-being of adolescents. Psychol Sci 28:204215. https://doi.org/10.1177/0956797616678438

Ramírez-Granizo IA, Ubago-Jiménez JL, González-Valero G, Puertas-Molero P, San Román-Mata S (2020) The effect of physical activity and the use of active video games: exergames in children and adolescents: a systematic review. Int J Environ Res Public Health 17:4243. https://doi.org/10.3390/ijerph17124243

Rebenitsch L, Owen C (2016) Review on cybersickness in applications and visual displays. Virtual Real 20:101-125. https://doi.org/10. 1007/s10055-016-0285-9

Rechichi C, De Mojà G, Aragona P (2017) Video game vision syndrome: a new clinical picture in children? J Pediatr Ophthalmol Strabismus 54:346-355. https://doi.org/10.3928/0191391320170510-01

Reid Chassiakos YL, Radesky J, Christakis D, Moreno MA, Cross C (2016) Children and adolescents and digital media. Pediatrics 138:e20162593. https://doi.org/10.1542/peds.2016-2593

Roettl J, Terlutter R (2018) The same video game in 2D, 3D or virtual reality - how does technology impact game evaluation and brand placements? PLoS ONE 13:e0200724. https://doi.org/10.1371/ journal.pone.0200724

Roley SS, Mailloux Z, Miller-Kuhaneck H, Glennon T (2007) Understanding ayres sensory integration ${ }^{\circledR}$. OT Pract $12: 1-8$

Rossi HS, dos Santos SM, Prates RO, Ferreira RAC (2018) Imaginator: a virtual reality based game for the treatment of sensory processing disorders. In: 2018 IEEE 6th international conference on serious games and applications for health (SeGAH). IEEE, pp 1-8

Resilient Educator (2020) Pros and cons: debating the usage of digital devices in the classroom. https://education.cu-portland.edu/blog/ classroom-resources/pros-and-cons-of-allowing-digital-devicesin-the-classroom/

Samsung (2020) Is the gear VR safe for children? https://www.samsu ng.com/uk/support/mobile-devices/is-the-gear-vr-safe-for-child ren/

Schneider LA, King DL, Delfabbro PH (2017) Family factors in adolescent problematic internet gaming: a systematic review. J Behav Addict 6:321-333. https://doi.org/10.1556/2006.6.2017.035

Segovia KY, Bailenson JN (2009) Virtually true: children's acquisition of false memories in virtual reality. Media Psychol 12:371-393. https://doi.org/10.1080/15213260903287267

Shaffer DW, Squire KR, Halverson R, Gee JP (2005) Video Games and the Future of Learning. Phi Delta Kappan 87:105-111. https://doi.org/10.1177/003172170508700205

Shaffer DR, Kipp K (2014) Developmental psychology: childhood and adolescence, 9th edn. Wadsworth Cengage Learning, Belmont

Slater M (2003) A note on presence terminology. Presence Connect 3:1-5

Slater M, Usoh M, Chrysanthou Y (1995) The influence of dynamic shadows on presence in immersive virtual environments. In: Göbel M (ed) Virtual environments '95. Springer, Vienna, pp $8-21$

Sobel K (2019) Immersive media and child development: Synthesis of a cross-sectoral meeting on virtual, augmented, and mixed reality and young children. The Joan Ganz Cooney Center at Sesame Workshop, New York

Sony Interactive Entertainment (2020) Health warnings. https:// www.playstation.com/en-us/network/legal/health-warnings/

Spence I, Feng J (2010) Video games and spatial cognition. Rev Gen Psychol 14:92-104. https://doi.org/10.1037/a0019491

Spielman RM, Jenkins WJ, Lovett MD (2020) Lifespan development. In: Psychology 2e. Rice University, Houston, Texas, pp 295-340

Standen PJ, Brown DJ (2006) Virtual reality and its role in removing the barriers that turn cognitive impairments into intellectual disability. Virtual Real 10:241-252. https://doi.org/10.1007/ s10055-006-0042-6

Stavropoulos V, Kuss DJ, Griffiths MD, Wilson P, Motti-Stefanidi F (2017) MMORPG gaming and hostility predict internet addiction symptoms in adolescents: an empirical multilevel 
longitudinal study. Addict Behav 64:294-300. https://doi.org/ 10.1016/j.addbeh.2015.09.001

Steve A, Grubb HJ (2018) The prevalence of ADHD in American Society: the influence of parent-child and child-technology interactions. Eur Sci J 14:41. https://doi.org/10.19044/esj. 2018.v14n8p41

Tate EB, Spruijt-Metz D, O'Reilly G, Jordan-Marsh M, Gotsis M, Pentz MA, Dunton GF (2013) mHealth approaches to child obesity prevention: successes, unique challenges, and next directions. Transl Behav Med 3:406-415. https://doi.org/10. 1007/s13142-013-0222-3

Thierer, AD, Camp, J (2017) Permissionless innovation and immersive technology: public policy for virtual and augmented reality. Mercatus Research Paper. https://doi.org/10.2139/ssrn. 3038935

Tosini G, Ferguson I, Tsubota K (2016) Effects of blue light on the circadian system and eye physiology. Mol vis 22:61-72

Turel O, Romashkin A, Morrison K (2016) Health outcomes of information system use lifestyles among adolescents: videogame addiction, sleep curtailment and cardio-metabolic deficiencies. PLoS ONE 11:e0154764. https://doi.org/10.1371/journal.pone. 0154764

Turel O, Romashkin A, Morrison KM (2017) A model linking video gaming, sleep quality, sweet drinks consumption and obesity among children and youth. Clin Obes 7:191-198. https://doi. org/10.1111/cob.12191

Tychsen L, Foeller P (2020) Effects of immersive virtual reality headset viewing on young children: visuomotor function, postural stability, and motion sickness. Am J Ophthalmol 209:151-159. https://doi.org/10.1016/j.ajo.2019.07.020

UK Department for Business Energy \& Industrial Strategy (2020) Safety of domestic virtual reality systems. The National Archives, Kew, London. https://www.gov.uk/government/publi cations/safety-of-domestic-virtual-reality-systems

Van Eck R (2006) Digital game-based learning: it's not just the digital natives who are restless. Educ Rev. https://doi.org/10.1145/ 950566950596

Vasa RA, Mazurek MO (2015) An update on anxiety in youth with autism spectrum disorders. Curr Opin Psychiatry 28:83-90. https://doi.org/10.1097/YCO.0000000000000133

Viner R, Davie M, Firth A (2019) The health impacts of screen time: a guide for clinicians and parents. R Coll Paediatr Child Health. https://www.rcpch.ac.uk/sites/default/files/2018-12/rcpch_ screen_time_guide_-_final.pdf

Volkow ND, Morales M (2015) The brain on drugs: from reward to addiction. Cell 162:712-725. https://doi.org/10.1016/j.cell.2015. 07.046

Wang C, Yu G (2018) Investigating the relationship between eye movement and brain wave activity using video games: pilot study. JMIR Ser Games 6:71-78. https://doi.org/10.2196/games.8908

Wang J, Li M, Zhu D, Cao Y (2020) Smartphone overuse and visual impairment in children and young adults: systematic review and meta-analysis. J Med Internet Res 22:e21923. https://doi.org/10. $2196 / 21923$
Weerdmeester J, Cima M, Granic I, Hashemian Y, Gotsis M (2016) A feasibility study on the effectiveness of a full-body videogame intervention for decreasing attention deficit hyperactivity disorder symptoms. Games Health J 5:258-269. https://doi.org/10. 1089/g4h.2015.0103

Weinstein AM (2017) An update overview on brain imaging studies of internet gaming disorder. Front Psychiatry. https://doi.org/10. 3389/fpsyt.2017.00185

Weinstein AM, Lejoyeux M (2020) Neurobiological mechanisms underlying internet and gaming disorder (IGD). Dialogues Clin Neurosci 22:113-126. https://doi.org/10.31887/DCNS.2020. 22.2/aweinstein

Weinstein A, Weizman A (2012) Emerging association between addictive gaming and attention-deficit/ hyperactivity disorder. Curr Psychiatry Rep. https://doi.org/10.1007/s11920-012-0311-x

Weiss MD, Baer S, Allan BA, Saran K, Schibuk H (2011) The screens culture: impact on ADHD. ADHD Atten Deficit Hyperact Disord. https://doi.org/10.1007/s12402-011-0065-z

Wichstrøm L, Stenseng F, Belsky J, von Soest T, Hygen BW (2019) Symptoms of internet gaming disorder in youth: predictors and comorbidity. J Abnorm Child Psychol 47:71-83. https://doi.org/ 10.1007/s10802-018-0422-x

Wong CW, Tsai A, Jonas JB, Ohno-Matsui K, Chen J, Ang M, Ting DSW (2020) Digital screen time during the COVID-19 pandemic: risk for a further myopia boom? Am J Ophthalmol 223:333-337. https://doi.org/10.1016/j.ajo.2020.07.034

Woolley JD, Ghossainy ME (2013) Revisiting the fantasy-reality distinction: children as Naïve skeptics. Child Dev 84:1496-1510. https://doi.org/10.1111/cdev.12081

World Health Organization (2018) International classification of diseases and related health problems (ICD-11). World Health Organization

World Health Organization (2020) Looking after our mental health. https://www.who.int/news-room/campaigns/connectingthe-world-to-combat-coronavirus/healthyathome/healthyath ome---mental-health

Yen J-Y, Ko C-H, Yen C-F, Wu H-Y, Yang M-J (2007) The comorbid psychiatric symptoms of internet addiction: attention deficit and hyperactivity disorder (ADHD), depression, social phobia, and hostility. J Adolesc Heal 41:93-98. https://doi.org/10.1016/j. jadohealth.2007.02.002

Young K (2009) Understanding online gaming addiction and treatment issues for adolescents. Am J Fam Ther 37:355-372. https://doi. org/10.1080/01926180902942191

Zaharias P, Chatzeparaskevaidou I, Karaoli F (2017) Learning geography through serious games: the effects of 2-dimensional and 3 -dimensional games on learning effectiveness, motivation to learn and user experience. Int J Gaming Comput Simul 9:28-44. https://doi.org/10.4018/IJGCMS.2017010102

Publisher's Note Springer Nature remains neutral with regard to jurisdictional claims in published maps and institutional affiliations. 